\title{
4. Unconventional Monetary Policy of THE ECB DURING THE FINANCIAL CRISIS: An Assessment and New Evidence
}

\author{
Christiaan Pattipeilohy, Jan Willem van den End, Mostafa \\ Tabbae, Jon Frost \& Jakob de Haan
}

\begin{abstract}
We first sketch how central banks have used unconventional monetary policy measures by using three indicators based on the composition of the balance sheet of eleven central banks. Our analysis suggests that although the ECB's balance sheet has increased dramatically during the crisis, the non-standard monetary policy measures had only a moderate impact on the composition of the ECB's balance sheet compared to other central banks, such as the Fed and the Bank of England. Next, we take stock of research analysing the effects of unconventional monetary policy of the ECB after the onset of the crisis. A crucial question is to what extent these measures have been able to affect interest rates, thereby restoring the monetary policy transmission process and supporting the central bank objectives. Finally, we offer new evidence on the effectiveness of the ECB's unconventional monetary policy measures, i.e. extended liquidity provision (LTRO) and the Securities Market Programme (SMP). Our results suggest that the LTRO interventions in general had a favorable (short-term) effect on government bond yields. Changes in the SMP only had a visible downward effect on bond yields in Summer 2011, when the program was reactivated for Italy and Spain, but this effect dissipated within a few weeks.
\end{abstract}

\subsection{INTRODUCTION}

Several central banks in industrialised countries have broadened their assortment of monetary policy instruments over the past few years. These so-called unconventional monetary policy measures were taken as more conventional measures had (largely) lost their potency. As pointed out by Borio and Disyatat (2010), the distinguishing feature of these measures is that the central bank actively uses its balance sheet to affect market prices and conditions beyond a short-term interest rate. For instance, after the Federal Open Market Committee (FOMC) had lowered the target for the federal funds rate to a range of 0 to 25 basis points in December 2008, US policymakers faced the challenge of how to further ease the stance of monetary policy as the economic outlook deteriorated. The Federal Reserve decided to purchase substantial quantities of assets with medium and long maturities in an effort to drive down private (long-term) borrowing rates. 
Other central banks took similar and other measures. For instance, recently the European Central Bank (ECB) announced a new program of outright monetary transactions (OMTs). The program involves discretionary sterilized purchases of short-term sovereign bonds under certain conditions and is subject to a prior request by the respective country's government for international assistance via the European Financial Stability Facility/European Stability Mechanism (EFSF/ ESM). Instead of explicitly driving down longer term borrowing rates, OMTs aim to restore a proper transmission of monetary policy throughout the euro area in case of severe market disruptions.

Unconventional monetary policy frameworks may comprise three elements: (i) large-scale liquidity support to banks; (ii) forward guidance of ultra-low policy rates over extended policy horizons; and (iii) large-scale financial market interventions, in particular huge asset purchases.

According to Hannoun (2012), "Large-scale interventions in financial markets aimed at reviving dysfunctional market segments or providing additional monetary stimulus have become routine. We should not underestimate the welcome role such policy actions played in the darkest days of the crisis. They were critical in preventing unfettered financial instability and a potential deflationary spiral. Extraordinary times call for extraordinary measures." However, he also warns that these measures "while justified and understandable as an exceptional response to the crisis, if prolonged, have adverse side effects that are likely to become more harmful the longer the 'medicine' is applied." Likewise, referring to the low interest rate policy of the Fed, Sachs (2012) argues that it "has a risk not acknowledged by the Fed: the creation of another bubble".

As a consequence of these unconventional measures, central bank balance sheets have expanded substantially. In advanced economies, central bank assets now exceed $20 \%$ of GDP (Figure 4.1; see also Hannoun (2012)) $)^{2}$. Moreover, unconventional monetary policies have led to significant changes in terms of balance sheet composition as is shown in Figure 4.2 (see Borio and Disyatat (2010) and Lenza et al. (2010) for further discussion). Unfortunately, given the different reporting methodologies by central banks on their balance sheets, the overview in Figure 4.2 does not allow us to make a more quantitative comparison of compositional changes in the balance sheets of different central banks.

In this chapter, after first briefly discussing conventional monetary policies, we will present an indicator-based methodology which does allow us to make such a

\footnotetext{
Negative side effects mentioned by Hannoun (2012) include: delaying balance sheet adjustments in the economy; the risk of encouraging a new round of risk-taking and leveraging in the financial system; concern that financial markets lose their capacity to discover prices; too dominant a role on the part of central banks in market-making could contribute to an atrophy of markets; and the longer the policies are in place, the harder the exit is likely to be.

2 Total of the euro area, Canada, Japan, Sweden, Switzerland, the United Kingdom and United States.
} 
Figure 4.1: Central Bank Assets as a percentage of GDP*

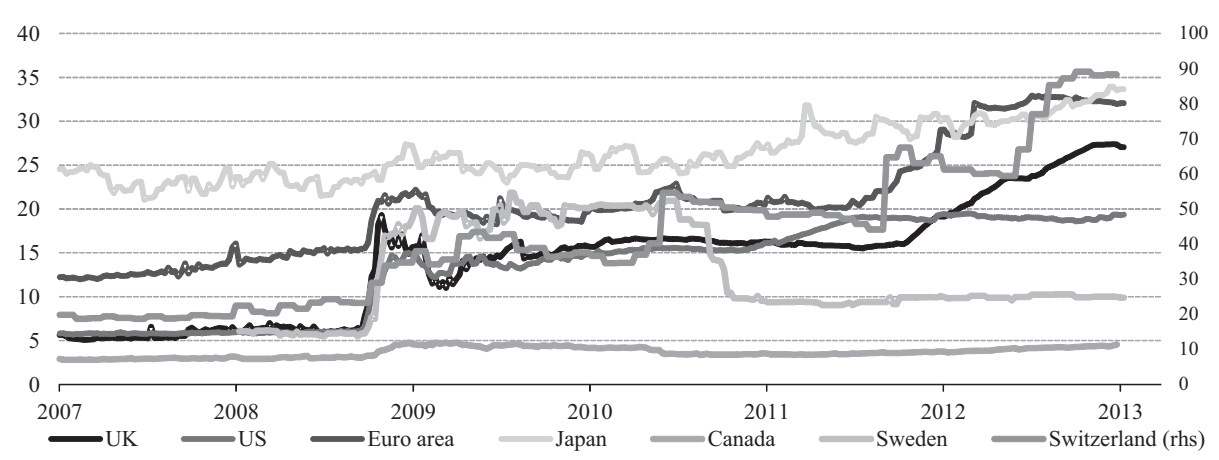

Nominal GDP in 2011

Figure 4.2: Central Bank Balance Sheets
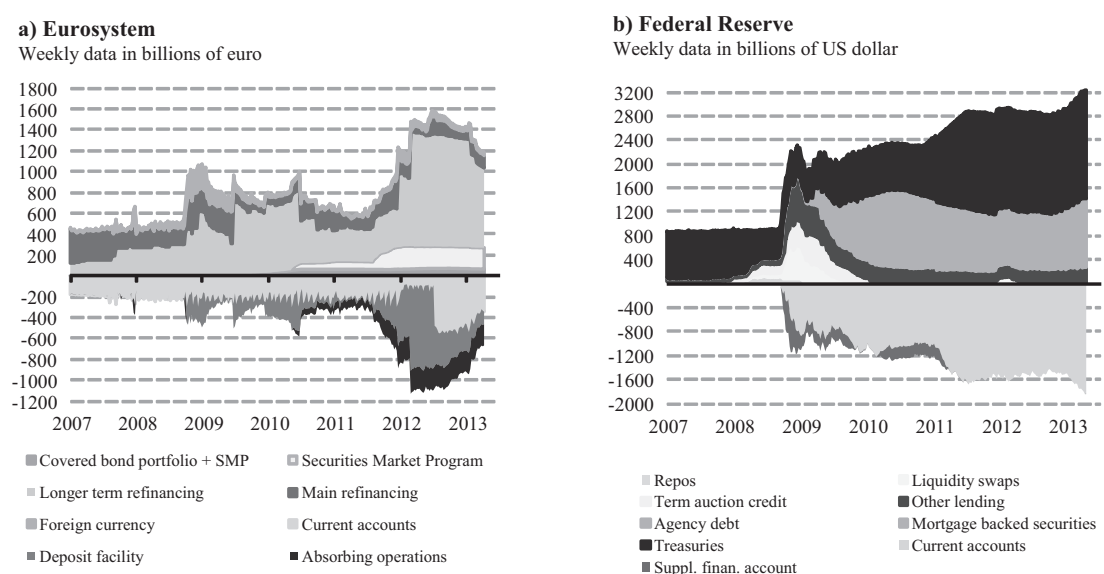

c) Bank of England

Weekly data in billions of GBP

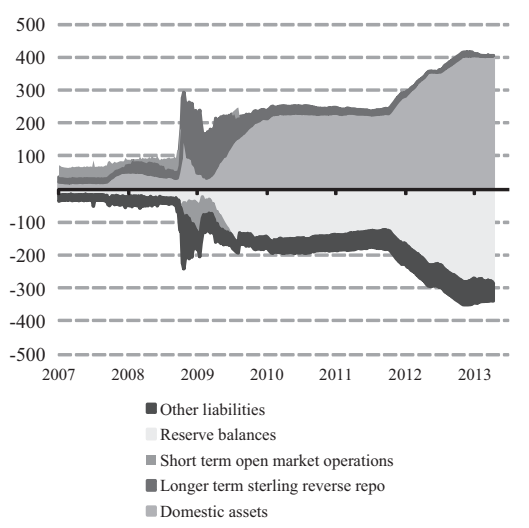

d) Bank of Japan
Monthly data in billions of yen

1500

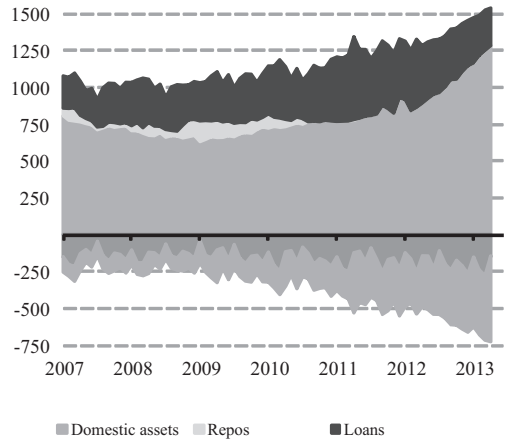

Domestic assets Repos - Loans

- Reverse repos ECurrent deposits 
comparison. The indicators have been calculated for central banks in several OECD countries: Australia, Canada, the euro area, Japan, Korea, Norway, Switzerland, Turkey, the UK, and the US. With these indicators we are able to quantify the scope of quantitative easing monetary policy measures, as well as the scale of qualitative easing. The indicators can be used to compare countries and to assess developments over time, while taking into account differences in starting positions in monetary policy frameworks. Our analysis suggests that while the ECB's balance sheet has increased dramatically during the crisis (both in nominal terms and as a percentage of GDP), the non-standard monetary policy measures had only a moderate impact on the composition of the ECB's balance sheet compared to other central banks such as the Fed and the Bank of England.

Next, we take stock of research analysing the effects of unconventional monetary policy of the ECB after the onset of the crisis ${ }^{3}$. A crucial question is to what extent these measures have been able to affect interest rates, thereby restoring the monetary policy transmission process and supporting the central bank objectives. We will discuss several recent studies addressing this question. An important element to investigate is related to the transmission channel of unconventional balance sheet policies. One channel could be through interest rate expectations, meaning that balance sheet policies represent a substitute to standard interest rate policy and contribute to forward guidance as in the New Keynesian framework. Another potential transmission channel could be through a portfolio-rebalancing effect. This would imply that balance sheet policies are complementary to standard interest rate policy in a Tobin preferred-habitat fashion. An answer to the question of which transmission channel dominates in practice could also provide an answer to the question of whether unconventional balance sheet policies are to be expected to remain part of the future standard monetary policy toolkit. A final question that will be touched upon is to what extent the (announcement) effects of asset purchase programs have waned over time.

The final part of the chapter provides new evidence on the effectiveness of the ECB's unconventional monetary policy measures, both extended liquidity provision and the Securities Market Programme (SMP). Under this programme, interventions were carried out in the euro area public and private debt securities markets to ensure depth and liquidity in dysfunctional market segments and to restore the proper functioning of the monetary policy transmission mechanism. Purchases of government bonds were strictly limited to secondary markets. To ensure that liquidity conditions are not affected, all purchases were fully neutralised through liquidity-absorbing operations. Using market data on bond yields, CDS spreads, money market spreads, stock price indices, exchange rates

\footnotetext{
For (reviews of the) evidence referring to other central banks, we refer to IMF (2009), Kluyev et al. (2009), Stone et al. (2011) and Kozicki et al. (2011).
} 
and volatility indicators, we seek to tease out the impact of policy interventions on yields and calculate "hypothetical yields" without such interventions.

\subsection{Conventional Monetary Policy: AN Overview}

Before zooming in on the ECB's non-conventional monetary policies since the start of the financial crisis in 2007, this section outlines some general developments in monetary policymaking before the crisis. Low and stable inflation became the primary (or even sole) objective of monetary policy of central banks in most industrialized countries ${ }^{4}$. However, the way central banks try to reach this objective differs across countries and has changed over time. Section 4.2.1. provides a broad-brush overview, while Section 4.2.2. zooms in on conventional monetary policies of the ECB.

\subsubsection{Inflation as Primary Objective}

According to the Mundell-Fleming model, a fixed exchange rate, capital mobility and national monetary policy cannot be achieved at the same time. One of the objectives has to give in. The Bretton Woods regime allowed for capital controls. But over time the effectiveness of capital controls was gradually diminishing. In a regime of a fixed exchange rates and free capital flows, money growth becomes endogenous. After the fall of the Bretton Woods regime, countries that opted for a flexible exchange rate had to decide on their monetary policy strategy. When inflation in several countries reached high levels during the 1970s, several central banks started to pay more attention to money growth, inspired by the monetarist adagio that inflation is always and everywhere a monetary phenomenon ${ }^{5}$.

According to Benatti and Goodhart (2010, p. 1178), the episode 1979-82 came to be known amongst central bankers under the general title of 'Practical Monetarism', characterised by:

"a) a belief in the medium and longer term reliability of the relationship between monetary growth and nominal incomes/inflation;

b) a belief that velocity (demand for money) functions were sufficiently predictable/stable to act as 'intermediate targets';

c) a belief that interest rate elasticities were such as to allow appropriate adjustments in both expenditure functions and monetary aggregates; d) a deep hostility to monetary base control methods."

\footnotetext{
The US is a clear exception in view of the "dual mandate" of the Fed for "maximum employment, stable prices and moderate long-term interest rates" (Federal Reserve Act, as amended in 1977).

5 Classic references include Friedman (1968), Johnson (1971) and Brunner and Melzer (1993).
} 
The monetary policy strategy of central banks should be considered against the background of their mandates. In the US, the "monetarist experiment" began in October 1979, when the FOMC under Chairman Paul Volcker adopted an operating procedure based on the management of non-borrowed reserves. "The intent was to focus policy on controlling the growth of M1 and M2 and thereby to reduce inflation, which had been running at double-digit rates. As you know, the disinflation effort was successful and ushered in the low-inflation regime that the United States has enjoyed since. However, the Federal Reserve discontinued the procedure based on non-borrowed reserves in 1982. It would be fair to say that monetary and credit aggregates have not played a central role in the formulation of U.S. monetary policy since that time, although policymakers continue to use monetary data as a source of information about the state of the economy." (Bernanke (2006)). As Bernanke points out, the reason that the Fed stopped relying on monetary aggregates is that in the United States, deregulation, financial innovation, and other factors have led to recurrent instability in the relationships between various monetary aggregates and inflation. Attempts to find stable relationships between M1 growth and growth in other nominal quantities were unsuccessful, and formal growth rate targets for M1 were discontinued in 1987. Similar problems showed up with broader aggregates, such as M2. The FOMC decided to discontinue setting target ranges for $\mathrm{M} 2$ and other aggregates after the statutory requirement for reporting such ranges lapsed in 2000. In continental Europe, the situation was very different. The Bundesbank, having a single mandate for price stability, introduced a policy of monetary targeting in 1974 which was widely considered to be very successful, even though the targets were frequently missed ${ }^{6}$. According to Beyer et al. (2009, pp. 19-20), there "were two main arguments in favour of providing a quantified guidepost for the future rate of monetary expansion. First and foremost was the intention of controlling inflation through the control of monetary expansion. Second, the Bundesbank tried to provide guidance to agents' (especially wage bargainers') expectations through the announcement of a quantified objective for monetary growth.

Although the formulation of the new strategy was heavily influenced by the ideas of the leading monetarists, the implementation of monetary targeting in Germany deviated from the theoretical blueprint in a number of ways. One important difference was that [the] Bundesbank did not formulate its targets in terms of the monetary base, but in terms of a broadly defined monetary aggregate, the central bank money stock (defined as currency in circulation plus the required minimum reserves on domestic deposits calculated at constant reserve ratios with base January 1974). Secondly, the Bundesbank did not attempt to control the money

\footnotetext{
In the period 1960-1998, average inflation in Germany was 3.1 per cent per year, which was far below inflation in other G7 countries. Only Switzerland came close with an average inflation rate of 3.3 per cent (Breyer et al., 2009).
} 
stock directly, but followed an indirect approach of influencing money demand by varying key money market rates and bank reserves (two-stage implementation procedure). Thirdly, the Bundesbank made it clear from the beginning that it could not and would not promise to reach the monetary target with any degree of precision."

Several other European countries pegged their currency to the German Mark (DEM) via the Exchange Rate Mechanism (ERM) of the European Monetary System (EMS). After an initial "turbulent period" (1979-1983), in which there were many rate adjustments, the ERM entered a "calmer" period (1983-1992), in which countries made maintenance of their peg to the DEM the centre-piece of their monetary policy ${ }^{7}$. After 1992 there were serious crises, which boosted the idea to introduce a common currency. Also the fact that the Bundesbank solely determined its policies based on the economic situation in Germany so that several countries faced an interest rate which was frequently not in line with their business cycle position gave impetus to the initiative for a monetary union.

Since 1999, the Governing Council of the ECB is in charge of monetary policymaking in the euro area. The Maastricht Treaty made price stability the ECB's primary objective, but left it to the Governing Council to give a precise meaning to this objective. The primary objective, first specified by the ECB as inflation less than 2 per cent in the euro area, was made more precise in 2003 following an internal evaluation of the ECB's monetary policy strategy. The ECB clarified that it aims for maintaining inflation "below but close to 2 per cent in the euro area in the medium term."

The ECB's monetary policy is based on a "two-pillar" strategy that explicitly pairs the discussion of monetary factors ("monetary analysis") with a broad-based non-monetary analysis of the risks to price stability in the short to medium run ("economic analysis"). According to the ECB (2011, p. 69), "the two-pillar approach is designed to ensure that no relevant information is lost in the assessment of the risks to price stability and that appropriate attention is paid to different perspectives and the cross-checking of information in order to reach an overall judgement on the risks to price stability". The two-pillar approach provides a cross-check of the indications that stem from the shorter term economic analysis with those from the longer term-oriented monetary analysis, which, according to the ECB, ensures that monetary policy does not overlook important information relevant for assessing future inflation trends. By taking policy decisions and evaluating their consequences not only on the basis of the short-term indications stemming from the analysis of economic and financial conditions but also on the basis of money and liquidity considerations, the ECB

\footnotetext{
See, for instance, Hilbers (1998) for an exposition of monetary policy in the Netherlands.
} 
arguably will not be tempted to take an overly activist course in determining the monetary policy stance (ECB (2011)).

The "economic analysis" focuses on the assessment of current economic and financial developments and the implied short to medium-term risks to price stability. Macroeconomic staff projections play an important role in the economic analysis, although their role is different from that of inflation forecasts in an inflation targeting strategy (see below). The ECB publishes these projections for the euro area four times a year in its Monthly Bulletin. The Governing Council uses them with many other pieces of information to assess the risks to price stability, but it neither assumes responsibility for the projections nor does it use the staff projections as its only tool for organising and communicating its assessment as done under Inflation Targeting.

The so-called "monetary analysis" focuses on a medium to long-term horizon. When the ECB's monetary policy strategy was introduced in 1998, the ECB Governing Council announced a quantitative "reference value" for the annual growth rate of a broad monetary aggregate (M3). This focus on money growth was motivated by the view that inflation in the long run is considered to be a mostly monetary phenomenon. The choice for M3 growth was justified by its perceived favourable empirical properties, especially a relatively stable money demand relationship. Furthermore, M3 growth was shown to exhibit leading indicator properties for future inflation. However, the ECB has always stressed that monetary policy does not react mechanically to deviations of M3 growth from the reference value. Such deviations, however, trigger increased efforts to identify and assess the underlying driving forces. Nowadays, the monetary analysis entails a comprehensive analysis of the liquidity situation, going well beyond M3 growth. For instance, the composition of M3 growth (i.e. the components and sectoral contributions) is extensively analysed.

In contrast to the ECB, several central banks opted for inflation targeting (hereafter, IT). IT was first introduced in 1989 in New Zealand as a monetary policy strategy. Since then, many countries started targeting inflation. By the end of 2009, 31 countries had adopted IT. According to Mishkin and Savastano (2001), IT involves the public announcement of numerical targets for inflation, a strong commitment of the central bank to price stability as a final monetary policy objective, and a high degree of transparency and accountability. The distinctive feature of this strategy is a forward-looking decision-making process known as "inflation-forecast targeting" (Svensson (1997)). It means that the central bank sets its policy instruments in such a way that its inflation forecast (after some time) equals the inflation target. Although in practice different forms of inflation targeting exist, they all have in common a published numerical inflation target and a predefined policy horizon. Central banks using this approach communicate 
monetary policy decisions in terms of a reaction to deviations in a forecast for a particular measure of inflation from the inflation target at a particular horizon. The central bank's forecast for inflation is therefore centrepiece both when it comes to decision-making and in communicating to the public. Several central banks of European countries outside the euro area use inflation targeting as their monetary policy strategy. For instance, both the Bank of England and the Riksbank (the central bank of Sweden) apply this strategy.

There is a large body of literature examining the consequences of IT, notably for inflation, which frequently comes to different conclusions ${ }^{8}$. After discussing this literature, Blinder et al. (2008, p. 935) conclude that "inflationary expectations appear to be generally well anchored, and inflation forecast errors small, in IT countries. And studies of countries undergoing regime changes suggest a causal link between adopting IT and anchoring inflation expectations. However, cross-sectional comparisons yield more ambiguous results; the choice of the control group is apparently crucial. So communication of an explicit inflation target is surely not the only way to anchor expectations."

No matter what their monetary strategy is, most central banks use two policy instruments: policy interest rates and open market operations. In the next section we will explain the use of the instruments in more detail for the case of the ECB.

\subsubsection{ECB Instruments 9}

The ECB provides two standing facilities, i.e. the marginal lending facility and the deposit facility. Banks can use these facilities if they need liquidity or if they want to stall liquidity. Both facilities have an overnight maturity and are available to banks on their own initiative. The deposit facility is used for mopping up liquidity from the banks at rates which normally are substantially below market rates. The marginal lending facility provides liquidity to the banks at rates that are usually substantially above market rates.

As the interest rates on the standing facilities are normally substantially higher (for borrowing) or lower (for depositing) than the corresponding money market rate, banks normally only use the standing facilities in the absence of other alternatives. As there are no limits on access to these facilities (except for the collateral requirements of the marginal lending facility), the rate on the marginal lending facility and the rate on the deposit facility normally provide a ceiling and a floor, respectively, for the overnight rate in the inter-bank money market. The standing facilities thus constitute a corridor for the inter-bank money market rate.

\footnotetext{
Also the literature on the factors that make a switch towards IT more likely yields very diverging results. See Samaryna and de Haan (2013) for a discussion.

9 This section heavily draws on de Haan et al. (2012).
} 
The ECB affects money market interest rates by providing more (or less) liquidity to banks if it wants to decrease (increase) interest rates. It allocates an amount of liquidity that allows banks to fulfil their liquidity needs at a price that is in line with the ECB policy intentions. To manage liquidity in the money market and steer short-term interest rates, it uses open market operations, i.e. it buys (or sells) financial assets. If assets are bought from (sold to) a bank, the reserves of that bank at the central bank increase (decrease). These operations are carried out by the National Central Banks (NCBs) in the euro area.

The most important open market operations of the ECB are the main refinancing operations (MROs) and longer-term refinancing operations (LTROs) (see Table 4.1). Lending through open market operations normally takes place in the form of reverse transactions. In these reverse transactions, the central bank buys assets from a bank under a repurchase agreement (i.e. the bank buys the asset back) or grants a loan against assets pledged as collateral. Reverse transactions are therefore temporary open market operations which provide funds for a limited, pre-specified period only. The ECB accepts instruments issued by both private and public debtors as collateral.

Table 4.1: Main monetary policy instruments of the ECB

\begin{tabular}{|c|c|c|c|c|}
\hline $\begin{array}{l}\text { Monetary policy } \\
\text { operations }\end{array}$ & $\begin{array}{l}\text { Liquidity } \\
\text { provision }\end{array}$ & $\begin{array}{l}\text { Liquidity } \\
\text { absorption }\end{array}$ & Maturity & Frequency \\
\hline \multicolumn{5}{|c|}{ Open market operations } \\
\hline $\begin{array}{l}\text { Main refinancing } \\
\text { operations }\end{array}$ & $\begin{array}{l}\text { Reverse } \\
\text { transactions }\end{array}$ & -- & One week & Weekly \\
\hline $\begin{array}{l}\text { Longer term } \\
\text { refinancing } \\
\text { operations }\end{array}$ & $\begin{array}{l}\text { Reverse } \\
\text { transactions }\end{array}$ & -- & $\begin{array}{l}\text { Three, six or } \\
\text { twelve months }\end{array}$ & Monthly \\
\hline \multicolumn{5}{|l|}{ Standing facilities } \\
\hline $\begin{array}{l}\text { Marginal lending } \\
\text { facility }\end{array}$ & $\begin{array}{l}\text { Reverse } \\
\text { transactions }\end{array}$ & -- & Overnight & $\begin{array}{l}\text { Access at } \\
\text { discretion of } \\
\text { counterparties }\end{array}$ \\
\hline Deposit facility & -- & Deposits & Overnight & $\begin{array}{l}\text { Access at } \\
\text { discretion of } \\
\text { counterparties }\end{array}$ \\
\hline
\end{tabular}

Source: ECB (2011)

In addition to the weekly MROs, the ECB also executes regular monthly LTROs with various maturities (e.g. six months or twelve months). These operations are aimed at providing longer-term liquidity to the banking system. After October 2008, the weight of the refinancing operations shifted towards LTROs. 
The final instrument that we discuss is the minimum reserve requirements imposed on banks. Under the minimum reserve system banks are required to hold compulsory deposits with NCBs. The amount of the required reserves is determined by the size and composition of the liabilities on the balance sheet of the bank concerned. For most liabilities included in the reserve base the reserve ratio is 2 per cent.

The minimum reserve system serves two main purposes: (1) to create sufficient structural demand for central bank credit, and (2) to contribute to the stabilisation of money market interest rates. The minimum reserve system enlarges the structural liquidity shortage of the banking system. The need for banks to hold reserves with the NCBs contributes to increasing the demand for central bank credit which, in turn, makes it easier for the ECB to steer money market rates through regular liquidity-providing operations. Interest rates are stabilized by allowing banks to use averaging provisions, i.e., to comply with reserve requirements on the basis of average daily reserve holdings over the maintenance period. This allows banks to smooth out daily liquidity fluctuations, since transitory reserve imbalances can be offset by opposite reserve imbalances generated within the same maintenance period.

As noted by González-Páramo (2011), the ECB’s Governing Council in practice made a clear distinction within its monetary policy framework between decisions on the monetary policy stance and the implementation of these decisions. This 'separation principle' implied that the Governing Council decided separately upon the monetary stance (by deciding on interest rates), while liquidity measures and open market operations were conducive to implementing this stance. This approach allowed the ECB to steer short-term interest rates close to the main policy rate, without risking that fine-tuning liquidity measures would be observed as changes in the stance of monetary policy.

\subsection{INDICATORS}

As pointed out by Borio and Disyatat (2010), before the financial crisis, monetary policy in most countries was defined exclusively in terms of a short-term interest rate. Under this framework, policymakers announce a desired level of the interest rate, while liquidity management operations ensure that a market "reference rate", typically an overnight rate, tracks the desired interest rate level closely ${ }^{10}$. As the central bank has a monopoly over bank reserves, it can set the quantity and the terms on which reserves are supplied at the margin. Therefore, the central

\footnotetext{
Only on a few occasions, central banks undertook short-lived liquidity injections to maintain stable systemic liquidity conditions. This happened, for instance, during the Long Term Capital Management (LTCM) crisis, the Y2K transition, and after the terrorist attacks of September 11, 2001.
} 
bank is able to set the opportunity cost ("price") of reserves, the overnight rate, to any desired level. Consequently, monetary policy can be implemented without large changes in the size of the central bank's balance sheet, which will be primarily driven by exogenous (autonomous) factors, such as the demand for cash by the public, government deposits, and reserve requirements.

When this conventional policy had (largely) lost its potency, central banks started affecting broader financial conditions more directly, actively using its balance sheet to that effect. These operations generally result in substantial changes in the size and composition of the central bank's balance sheet. Following Lenza et al. (2010), theoretically a distinction can be made between quantitative and qualitative easing. The first entails an expansion of the central bank balance sheet, while it does not alter the composition of the asset side of the balance sheet. So the portfolio of assets held by the central bank is not changed: the share of each asset category in total holdings does not alter substantially and no new asset classes are added to the portfolio. The increase in the monetary base is reflected in an accumulation of central bank reserves. Under qualitative easing, the overall size of the central bank balance sheet is left untouched, but the composition of asset holdings is changed. According to Lenza et al. (2010), nonconventional policies consisted mainly of qualitative easing until the failure of Lehman, while thereafter central bank balance sheets expanded strongly (even as the composition of the asset side continued to evolve), implying a combination of both quantitative and qualitative easing.

The size and composition of a central bank balance sheet can therefore be used as an indicator of the aggressiveness of the policy efforts of the monetary authorities. Based on a stylised balance sheet of a central bank (see Table 4.2), some simple balance indicators to characterise monetary policy strategies can be developed. The assets side of the balance sheet of a central bank usually consists of domestic government debt, domestic private sector debt (generally banks) and foreign exchange reserves (including gold). The principal category on the liabilities side is base money (M0), i.e. bank notes (Bn) plus non-cash reserves that banks hold with the central bank (Res).

Using the information on the central bank's balance sheet, we develop three indicators. The first of these is the ratio between domestic government debt and domestic private sector debt $(\mathrm{G} / \mathrm{L})$ that shows through which domestic channel a central bank implements its monetary policy. The second indicator is the ratio between domestic assets and foreign exchange reserves $[(\mathrm{G}+\mathrm{L}) / \mathrm{FX}]$ to evaluate the extent to which monetary policy is tuned to the external environment. Finally, on the liabilities side we will have a look at the ratio between bank reserves and bank notes (Res/Bn) as an indicator of the level of bank liquidities (as part of M0). 
Table 4.2: Stylised central bank balance sheet

\begin{tabular}{ll|lc}
\hline Assets & & Liabilities & \\
\hline Domestic government debt & G & Bank notes & Bn \\
$\begin{array}{l}\text { Domestic private sector debt } \\
\begin{array}{l}\text { Foreign exchange reserves } \\
\text { (including gold) }\end{array}\end{array}$ & L & Reserves & Res \\
\hline
\end{tabular}

The indicators can be used to characterise and classify central banks and their methods of implementing monetary policy along three dimensions. To this end, we have calculated the indicators for eleven central banks in OECD countries. We have collected data from the central banks' annual accounts for 2006 year-end (before the crisis) and end-2011 (during or post crisis).

Figures 4.3 and 4.4 show the three indicators in two dimensions. The vertical axis in each case shows our indicator of the liabilities side of the balance, i.e. Res/Bn (note that axes have logarithmic scales). An upward movement along the vertical axis means that demand deposits held by banks at their respective central bank increase relative to banknotes in circulation ${ }^{11}$. The horizontal axis in Figure 4.3 shows the ratio between government debt and private sector debt $(\mathrm{G} / \mathrm{L})$. A central bank operating on the left hand side of the diagram thus holds more private debt, while a central bank on the right hand side of the diagram has more government debt on its balance sheet. Hence, a central bank entering in the left hand side of the diagram may be considered a bankers' bank ${ }^{12}$, while a central bank entering in the right hand side could be classified as a monetary financier ${ }^{13}$. The horizontal axis in Figure 4.4 shows the ratio between domestic debt and foreign exchange reserves, i.e. $(\mathrm{G}+\mathrm{L}) / \mathrm{FX}$. A central bank operating on the left hand side of the diagram holds a relatively large amount of foreign exchange reserves; such a bank will therefore be classifies as FX-hoarder. A central bank active on the right hand side holds mainly domestic debt and will be classified as a domestic lender-of-last-resort (which may apply either to domestic banks or domestic governments, as reflected in Figure 4.3).

Figures 4.5 and 4.6 show that central banks in 2006 had widely varying starting positions in terms of domestic government debt and domestic private sector debt held. In terms of the terminology of Figures 4.3 and 4.4 one half of the central banks can be classified as bankers' banks, while the other half in fact operates as monetary financier. Their starting positions are also very diversified in terms of

11 For our purposes this will also include longer term central bank liabilities held by monetary financial institutions, such as fixed term deposits and central bank debt certificates issued.

In principle, private sector debt may also include non-bank debt, e.g. corporate bonds or instruments issued by SPVs.

13 These definitions are for illustrative purposes only and completely unrelated to other similar concepts, e.g. the legal definition of monetary financing as in Article 123 of the Treaty on the Functioning of the European Union. 
Figure 4.3: Domestic composition central bank balance sheet

Horizontal axis refers to ratio of domestic public sector debt to domestic private sector debt. Vertical axis refers to ratio of reserves to banknotes.

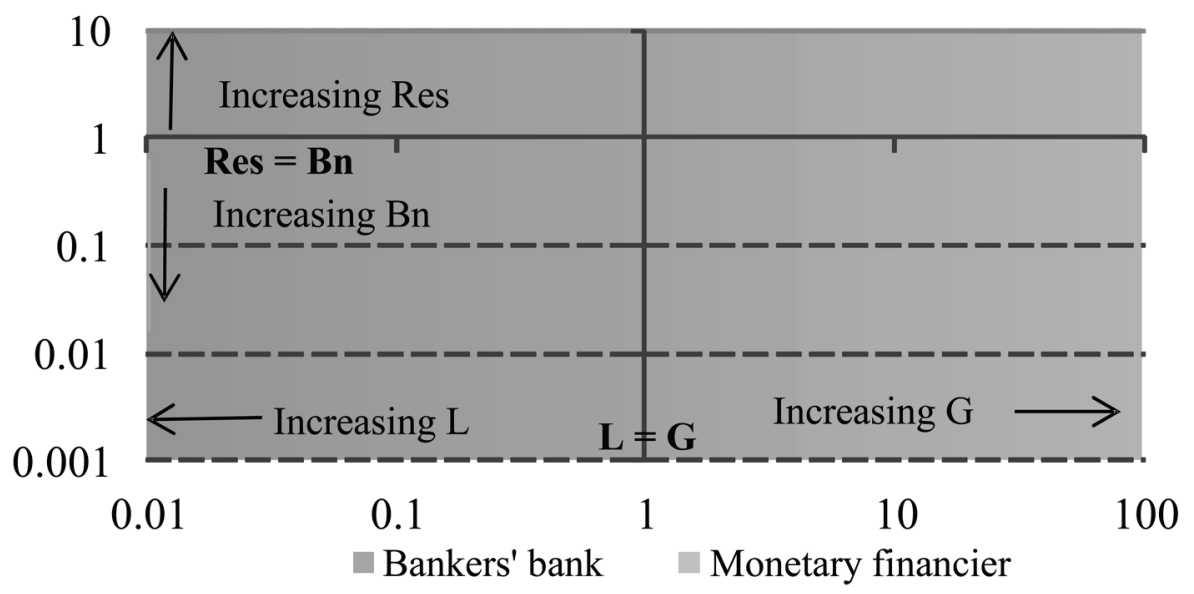

Note: Log scales. G=domestic public sector debt, $\mathrm{L}=$ domestic private sectordebt, Res=bank reserves, Bn=banknotes.

Figure 4.4: International composition central bank balance sheet

Horizontal axis refers to ratio of domestic assets to foreign assets.

Vertical axis refers to the ratio of reserves to banknotes. See also Figure 4.1.

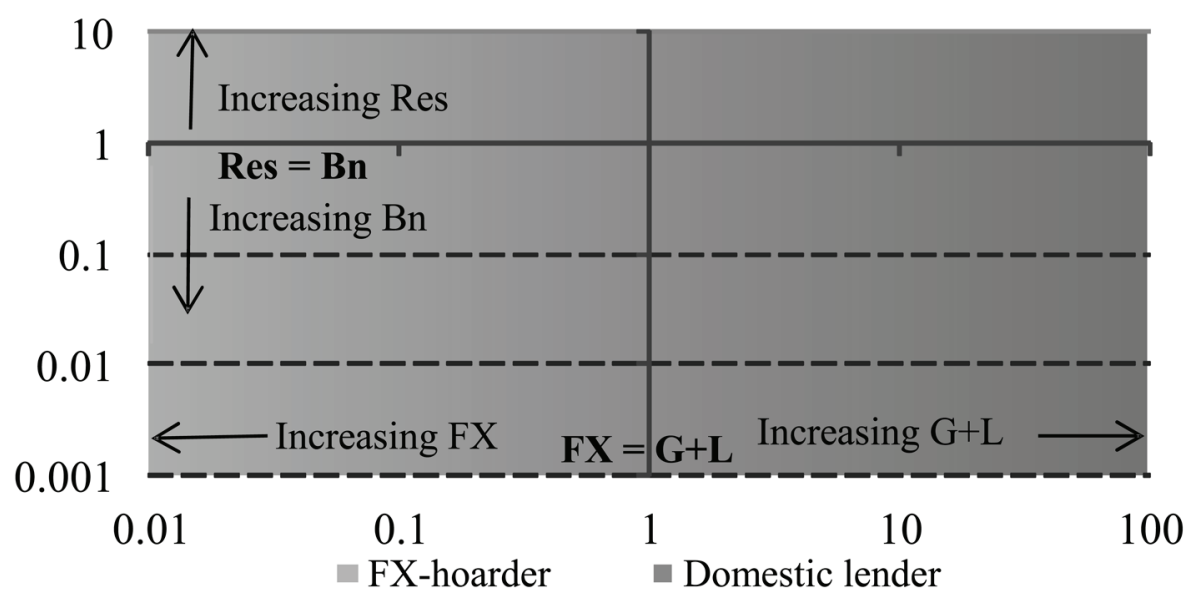

Note: Log scales. $\mathrm{G}+\mathrm{L}=$ domestic debt, $\mathrm{FX}=$ foreign exchange reserves (including gold), Res=bank reserves, $\mathrm{Bn}=$ banknotes.

liquidity provision to banks. This is mainly due to diverging reserve requirements. In some regions (e.g. the euro area) reserve requirements apply to a large number of banks, while these are far less relevant in other countries (e.g. the US). 
Figure 4.5: Domestic orientation central banks in 2006 and 2011

Horizontal axis refers to the ratio of domestic public sector debt to domestic private sector debt. Vertical axis refers to ratio of reserves to banknotes. See also Figure 4.1.

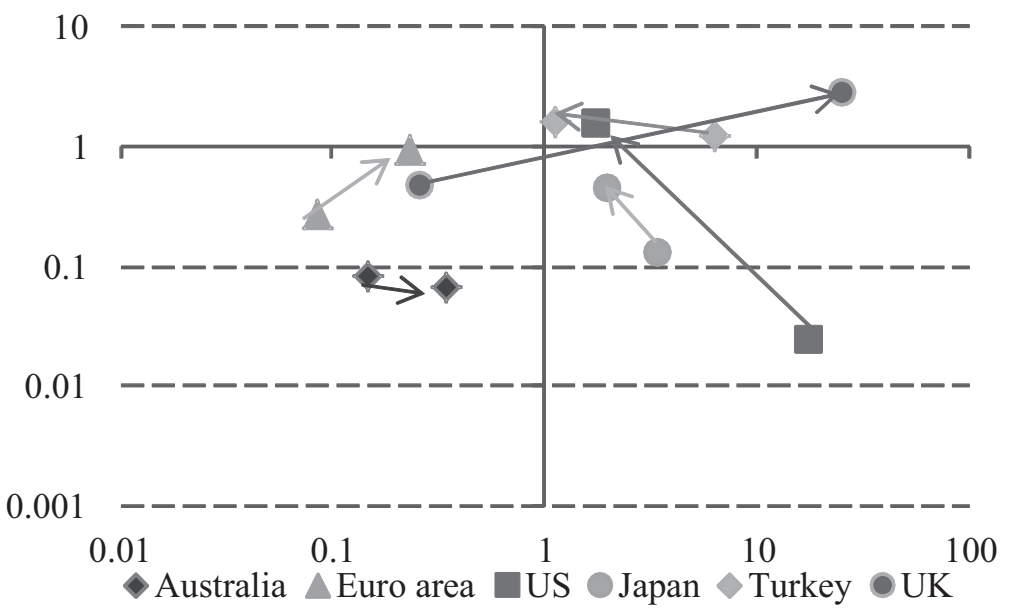

Figure 4.6: Domestic orientation central banks in 2006 and 2011

Horizontal axis refers to the ratio of domestic public sector debt to domestic private sector debt. Vertical axis refers to ratio of reserves to banknotes. See also Figure 4.1.

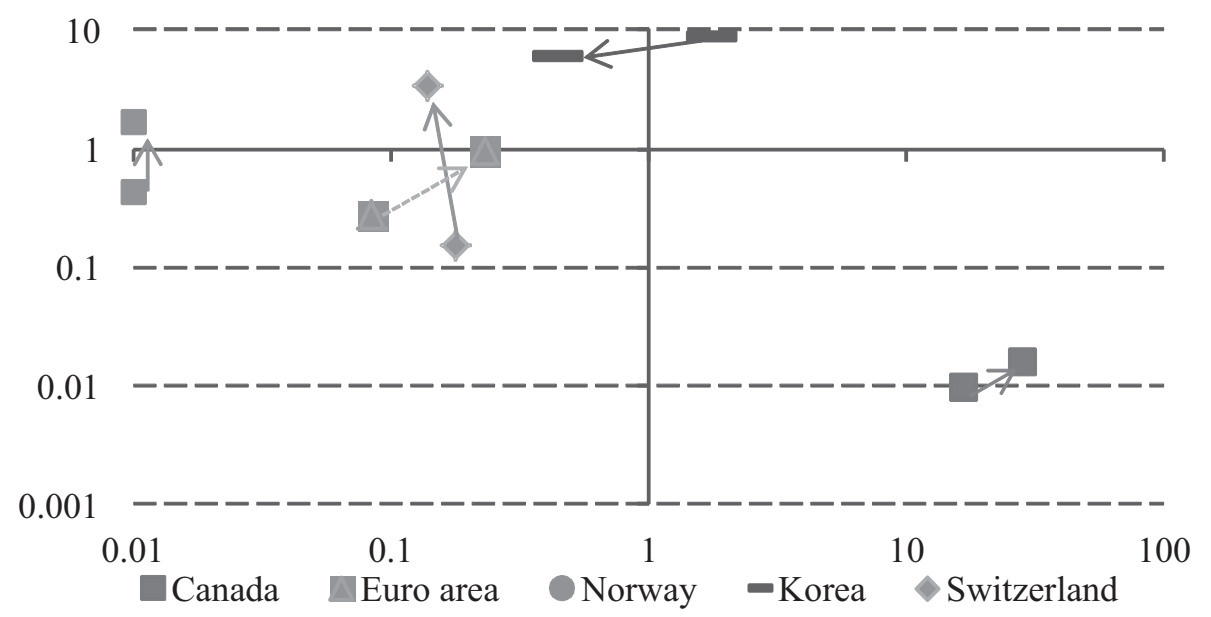

Note: Observation of G/L for Norway is smaller than 0.01 both in 2006 and 2011

Figures 4.5 and 4.6 also show that between 2006 and 2011 a large number of central banks converged towards each other in terms of the domestic public and private sector debt that they hold. Central banks that used to focus mainly on the bank credit channel increased their exposure to the domestic government and the 
other way around. In this process, most central banks converge towards a more balanced ratio between public and private sector debt $(\mathrm{L}=\mathrm{G})$. A striking exception is the UK where the ratio between public and private sector debt has overshot much more, causing the Bank of England to change from a bankers' bank into a monetary financier. A reverse trend can be seen in South Korea, although it is much less pronounced. The observed patterns are in line with the different guises of the recent crisis which set in from mid-2007. First, central banks were confronted with a global banking crisis, which led them to expand their lending to banks. This caused a change in balance sheet composition in particular for central banks which had implemented their monetary policy through sovereign debt markets before the crisis (e.g. the Fed, the Bank of Japan and the Central Bank of Turkey). Second, as the crisis was followed by expansionary fiscal policies causing strong increases in sovereign debt levels and - in some cases upward pressures on interest rates, central banks developed purchasing programmes for sovereign debt. The largest impact in terms of balance sheet composition of the latter development is observed for central banks which did not target sovereign debt markets before (e.g. the ECB, the Bank of England and the Reserve Bank of Australia).

At the same time the provision of liquidity to banks has expanded relative to bank notes in circulation in almost all regions. This means that most central banks do not or hardly sterilise the surplus liquidity resulting from new liquidity provision programmes by reducing other central bank assets. The provision of liquidity to banks expanded most sharply in the US and Switzerland. Australia and South Korea are the exception to the rule as liquidity provision fell off slightly in these two countries.

As Figures 4.7 and 4.8 show, the starting positions of the central banks considered also vary widely in terms of the ratio between domestic and foreign assets. There are a number of central banks holding virtually only domestic assets (Canada, US and Japan). Most other central banks in 2006 had a more balanced position in terms of domestic versus foreign currencies. Norway is an outlier in this respect and in 2006 could be classified as a real foreign exchange hoarder.

Between 2006 and 2011, the ratio between domestic and foreign assets shifted significantly in three countries. Switzerland and South Korea bought up large quantities of foreign currency relative to their domestic assets, while the reverse holds true for the UK ${ }^{14}$. In Switzerland and South Korea this goes hand in hand with efforts to stabilise the exchange rate. The Bank of England has become more inwardly directed since the crisis (mainly government debt). For other central

\footnotetext{
In South Korea and Norway the change in domestic assets (numerator-effect) contributes almost to the same extent as the change in currency reserves (denominator-effect). The denominator effect dominates in Switzerland, whereas in the UK the numerator effect is more important.
} 
Figure 4.7: Foreign orientation central banks in 2006 and 2011

Horizontal axis refers to the ratio of domestic assets to foreign exchange reserves. Vertical axis refers to ratio of reserves to banknotes. See also Figure 4.2.

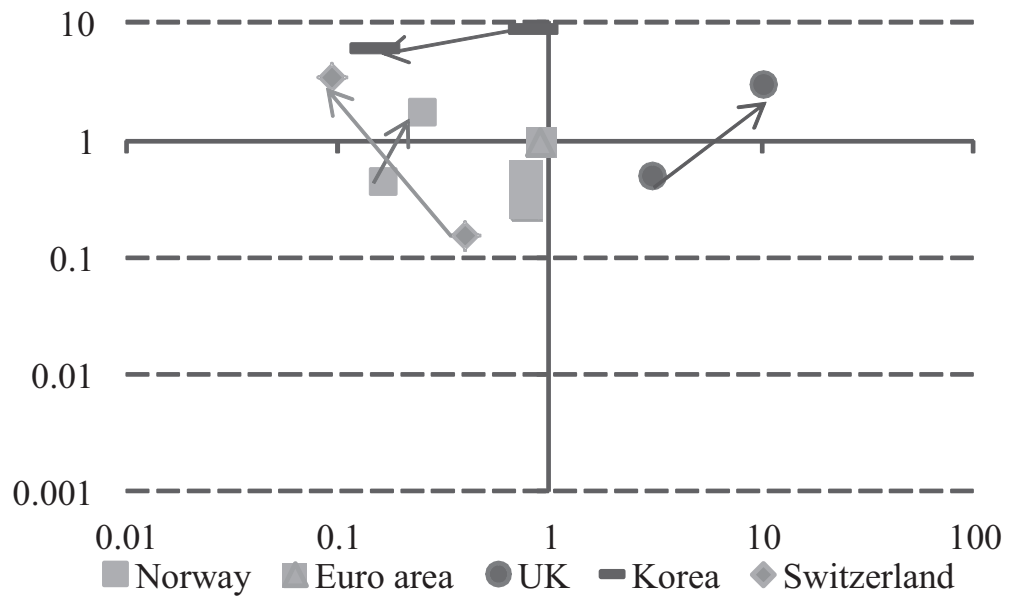

Figure 4.8: Foreign orientation central banks in 2006 and 2011

Horizontal axies refers to the ratio of domestic assets to foreign exchange reserves. Vertical axis refers to ratio of reserves to banknotes. See also Figure 4.2.

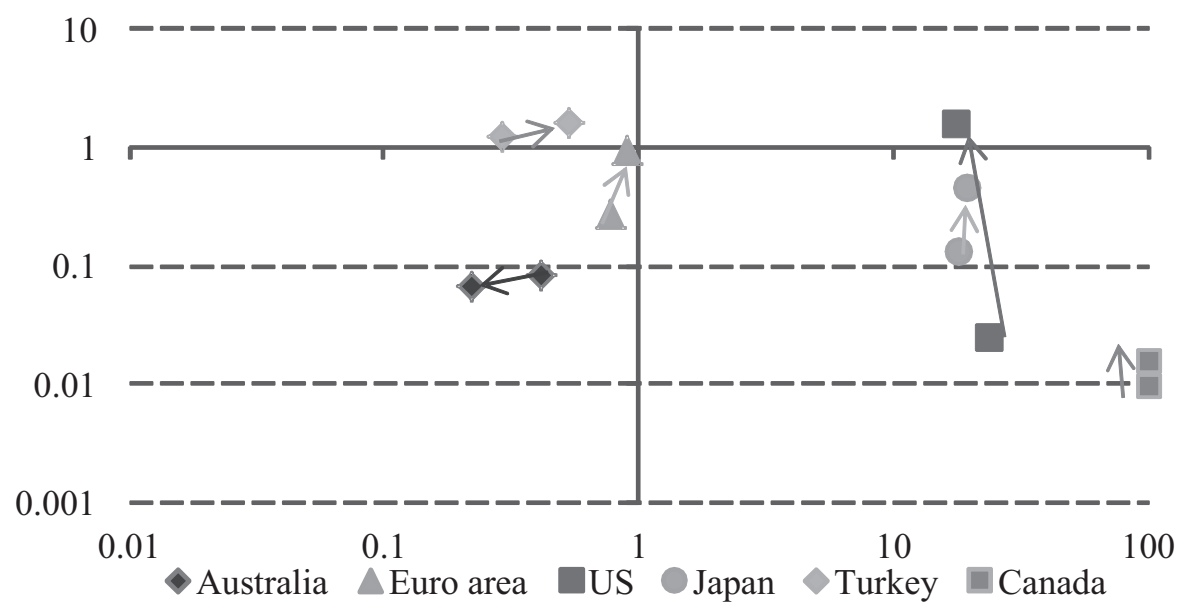

Note: Observation of $(\mathrm{G}+\mathrm{L}) / \mathrm{FX}$ for Canada is larger than 100 both in 2006 and 2011.

banks, the ratio between domestic and foreign assets has remained virtually unchanged.

A combined indicator can be used to map out to which extent the measures taken deviate from the regular (pre-crisis) implementation of monetary policy. To this end, we have calculated the distance that central banks cover along the three 
indicators ${ }^{15}$. It should be noted that these indicators only depict the distance covered and not the direction they take.

Figure 4.9 shows that central banks that are most aggressive in terms of balance sheet size are not necessarily the most aggressive in terms of composition. The Bank of England, the Fed and the Swiss National Bank are among the most aggressive central banks in terms of composition, for instance, meaning that their interventions are the furthest removed from their regularly employed framework. For the UK the adjustment has mostly taken place in the increased attention for government debt (the black bar). In the US and in Switzerland the strong increase in the provision of liquidity is especially noticeable (the dark grey bar).

Figure 4.9: Measure for change in monetary policy implementation based on composite balance sheet indicator

Distance in $[(\mathrm{G}+\mathrm{L}) / \mathrm{FX}$ - G/L - Res/Bn]- space between end-2006 and end-2011 including contribution per indicator. For reference the ratio of the total central bank assets in 2011 relative to 2006 is also included.

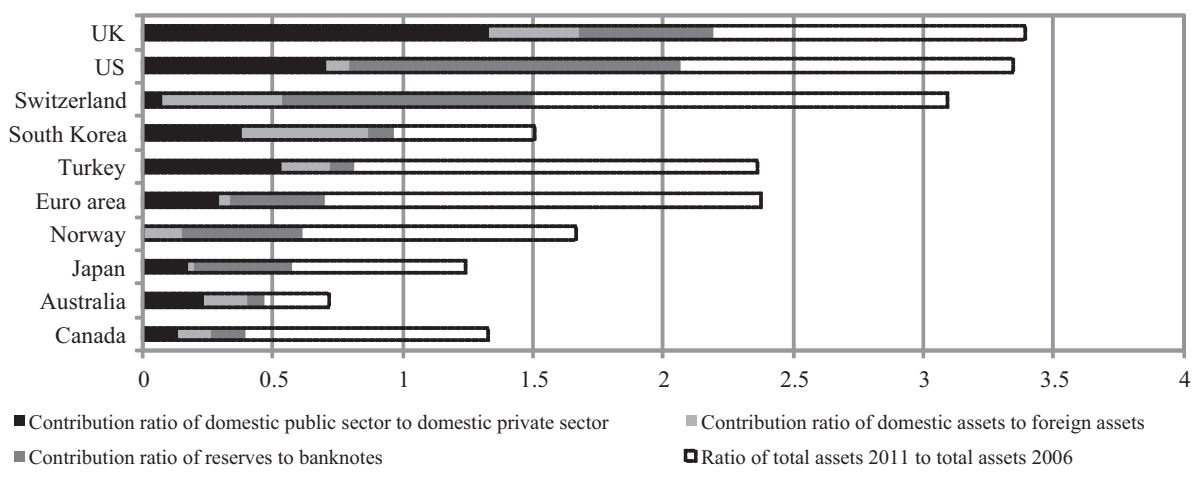

In our framework the ECB takes a more intermediate position. The most important driver in the change in balance sheet composition of the ECB relates to the increase in bank liquidity (the dark grey bar), which refers to the increased intermediary role of the ECB in the interbank market which collapsed in 2008. However, given the fact that the supply of liquidity to banks was already relatively abundant before the crisis, the change in the composition of the ECB's balance sheet is smaller than e.g. the change observed in the composition of the Fed's balance sheet (even though the level of bank reserves relative to banknotes is comparable in 2011). Moreover, the increase in liquidity was achieved to a

\footnotetext{
We have calculated the length of the vector in the three dimensional $[(\mathrm{G}+\mathrm{L}) / \mathrm{FX}-\mathrm{G} / \mathrm{L}-\mathrm{Res} / \mathrm{Bn}]$ space between 2006 and 2011. Under the condition that the value of the indicators is larger than zero and smaller than infinity, a central bank can position itself on every coordinate in the $[(\mathrm{G}+\mathrm{L}) / \mathrm{FX}-\mathrm{G} / \mathrm{L}-\mathrm{Res} / \mathrm{Bn}]$-space. A movement in one dimension can take place independent of movements in the other two dimensions. One single policy measure may, however, have multi-dimensional consequences.
} 
large extent through channels which are traditionally the focus of the ECB's monetary policy, i.e. lending operations to banks. Considering the relatively small amounts of government bonds purchased by the ECB thus far the change in the composition of the ECB's domestic assets (the black bar) has been relatively mild compared to other more aggressive central banks.

\subsection{RECENT RESEARCH ON THE ECB'S UnCONVENTIONAL Policies: A SURVEY}

\subsubsection{ECB Policies}

In the beginning of the financial crisis, the ECB did not reduce its policy rates. But after the demise of Lehman Brothers it reduced its key interest rates to historically low levels. The main refinancing rate was cut by a total of 325 basis points to 1 per cent between October 2008 and May 2009. In addition, the Governing Council adopted a number of temporary non-standard measures, subsequently referred to as the Enhanced Credit Support, focusing primarily on banks. Due to uncertainty about the creditworthiness of other banks, the inter-bank market did not function properly. After the failure of Lehman Brothers in September 2008 the inter-bank market effectively shut down. Amid significantly impaired markets and elevated counterparty credit concerns, demand for liquidity rose sharply while interbank lending declined rapidly. There are five main building blocks of the Enhanced Credit Support:

(1) Unlimited provision of liquidity through "fixed rate tenders with full allotment" in both the main refinancing operations (MROs) and the long-term refinancing operations (LTROs). Thus, contrary to normal practice, banks had unlimited access to central bank liquidity at the main refinancing rate, subject to adequate collateral.

(2) Extension of the (already long) list of collateral assets, so that the share of private sector assets increased to 56 per cent of the nominal value of securities on the list.

(3) Extension of the maturity of LTROs, initially to six months, and then, in late June 2009, to twelve months, aiming to decrease uncertainty in commercial banks' liquidity planning.

(4) Liquidity provision in foreign currencies, particularly U.S. dollars, through swap lines with the Federal Reserve. This measure supported banks which otherwise faced a massive shortfall in US dollar funding during the financial crisis.

(5) Covered Bonds Purchase Programmes $(\mathrm{CBPPs})^{16}$. The covered bonds market

16 There were, in fact, two rounds: CBPP which ended in June 2010 and CBPP2 which started in November 2011. 
had virtually dried up in terms of liquidity, issuance and spreads. The aim of the programme was to revive the covered bond market, which is a very important financial market in Europe and a primary source of financing for banks. At the end of 2012 the amount outstanding was 68.4 billion euro ${ }^{17}$.

Throughout the provision of Enhanced Credit Support the separation principle described in Section 4.2.2. has been maintained by the ECB. Interest rate setting remained conducive to setting the stance of monetary policy, while the special liquidity measures aimed at ensuring the transmission of policy rates through the euro area banking sector and ultimately households and non-financial corporations (González-Páramo (2011)).

On 10 May 2010 the ECB launched the Securities Market Programme (SMP) "to address the severe tensions in certain market segments". The ECB started to intervene in the secondary market of some euro area government bonds in order "to ensure depth and liquidity" and "restore an appropriate monetary policy transmission mechanism". After a first wave of interventions, the programme was re-activated in August 2011, in response to renewed tensions. The primary goal of the SMP was to address a malfunctioning of certain market segments by ensuring sufficient depth and liquidity. It was believed that these severe market tensions, if left untreated, would create unacceptable downside risks to price stability. The decision to establish the SMP was not accompanied by explicit targets in terms of volumes to be purchased or yield levels to be attained. ECB policy-makers emphasised on several occasions that the purpose of the SMP was not to change the monetary policy stance, which continued to be driven by the key policy rates (Manganelli (2012)). The SMP was terminated with the introduction of OMTs (see below). The existing securities in the SMP portfolio will be held to maturity. At the end of 2012 the amount of government securities at the ECB balance sheet due to the SMP was EUR 208.3 billion $^{18}$.

In November and December 2011, the ECB Governing Council reduced interest rates in two steps of 25 basis points. The refinancing interest rate came down from 1.50 to 1.00 per cent. These rate cuts were deemed necessary in view of the worsened economic forecasts which indicated increased recession risk. The ECB in addition introduced liquidity-enhancing measures in order to strengthen the liquidity position of European banks. It introduced two LTROs with a maturity of 36 months and the option of early repayment after one year. In December 2011, the ECB lent almost EUR490 billion to banks. In February 2012, the ECB lent almost EUR 530 billion. Whereas the number of banks participating in the first LTRO was 523, in the second LTRO 800 banks asked for and received threeyear loans. Banks considered three-year central bank funding at favourable rates

17 Source: www.ecb.int/mopo/implement/omo/html/index.en.html (accessed 27 December 2012).

18 Source: www.ecb.int/mopo/implement/omo/html/index.en.html (assessed 27 December 2012). 
as a very attractive way of funding current and new business. In addition to introducing these LTROs, the Governing Council in its December 2011 meeting decided to extend the list of eligible collateral and to temporary reduce the reserve ratio from 2 to 1 per cent.

Finally, on 2 August 2012, the Governing Council of the ECB announced its intention to perform Outright Monetary Transactions (OMTs) in secondary sovereign bond markets that aim at safeguarding an appropriate monetary policy transmission and the singleness of the monetary policy ${ }^{19}$. A necessary condition for OMTs is strict and effective conditionality attached to an appropriate European Financial Stability Facility/European Stability Mechanism (EFSF/ESM) programme. Such programmes can take the form of a full EFSF/ESM macroeconomic adjustment programme or a precautionary programme (Enhanced Conditions Credit Line), provided that they include the possibility of EFSF/ESM primary market purchases. Transactions will be focused on the shorter end of the yield curve, and in particular on sovereign bonds with a maturity of between one and three years. Importantly, no ex ante quantitative limits are set on the size of OMTs. OMTs will be fully sterilized.

\subsubsection{Transmission}

Several transmission mechanisms of unconventional policies can be identified (Borio and Disyatat (2010); Lenza et al. (2010) and Joyce et al. (2011)).

First is the signalling channel. Similar to conventional monetary policy (see Blinder et al. (2008)), the communication of unconventional policies is an integral part of their transmission mechanism. In the standard New Keynesian framework (cf. Eggertsson and Woodford (2003)), the composition of the central bank's balance sheet may only affect the monetary stance and monetary transmission through its signalling effect about the future policy rate. Communication about operations undertaken by the central bank influence public expectations about key factors that underpin an asset's market valuation, such as expectations regarding the future course of policy, relative scarcities of different assets, or their risk and liquidity profiles. Communication may manage expectations of the path of future monetary policy decisions and thus affect the slope of the money market yield curve. Also the announcement that the central bank will engage in operations involving illiquid assets may in itself boost investor confidence in those assets, thereby reducing liquidity premia. Likewise, in the case of the euro area, communications by the ECB may affect market perceptions of tail risks, as exemplified by market reactions to the announcement of the OMTs. If particular

19 See www.ecb.int/press/pr/date/2012/html/pr120906_1.en.html. 
measures are anticipated, investors will price them in even before the specifics are announced. As a result, policy announcements will affect yields only if they deliver a surprise to the market.

Second, liquidity provision to banks may influence the level of very short-term interest rates through liquidity effects in the interbank money market. To the extent that such measures result in excess central bank liquidity accumulating in the market, unconventional policies can cause a spread between the key policy rate (i.e. the MRO rate in the ECB context) and the overnight market rate (EONIA). Also the pricing of financial instruments of more relevance for macroeconomic developments may be affected. For instance, spreads on important market interest rates (such as EURIBOR or LIBOR, which form the basis for many private credit contracts) can be reduced for a given level of the key policy rates, thereby stimulating private spending.

Finally, central bank asset purchases may impact the composition of private sector portfolios. Following Borio and Disyatat (2010), this can be referred to as broad portfolio balance channel. Under the expectations hypothesis and canonical arbitrage-free models of the term structure, asset purchases by the central bank will not affect yields. But in models that account for imperfect asset substitutability or preferred-habitat investors, changes in relative supplies brought about by central bank operations may affect the composition of portfolios and alter behaviour. For instance, Greenwood and Vayanos (2008) argue that central bank interventions may affect the term structure by changing the total quantity of duration risk that arbitrageurs must hold. When debt in public hands increases or shifts toward longer maturities, market participants are more exposed to shifts in interest rates and require higher premia to bear this extra risk. Following D'Amico and King (2012) this result can be called duration effect. D'Amico and King (2012) develop a model for what they call a localsupply effect, building upon the preferred habitat model of Vayanos and Vila (2009). In this model, preferred-habitat investors have exogenously given demand curves for securities with different maturity, and they do not trade across different maturities. In contrast, arbitrageurs do trade across different maturities and render the term structure arbitrage-free in equilibrium by buying securities that are in low demand and selling those that are in high demand, but risk aversion prevents them from engaging in this process until expected returns are equated across securities. Thus, exogenous shocks to preferred-habitat demand can have effects on prices. Within this framework, D'Amico and King (2012) distinguish two ways in which central bank asset purchases might operate: stock effects and flow effects. Stock effects are defined as persistent changes in prices that result from movements along government bond demand curves. Flow effects are defined as the response of prices to the ongoing purchase operations and could reflect, on top of portfolio rebalancing activity due to the outcome of the 
purchases, impairments in liquidity and functioning that lead to sluggish price discovery. Cúrdia and Woodford (2011) demonstrate that the portfolio-channel may also become relevant in a New Keynesian setting with imperfect asset substitutability. However, in their model this may only be relevant in case of severe market disruptions and with targeted asset purchases by the central bank, while quantitative easing in the strict sense remains ineffective.

A final example is provided by De Pooter et al. (2012). These authors develop a search-based asset-pricing model with default in which the asset's fundamental value is affected by liquidity risk, i.e. the risk that an agent cannot immediately sell an asset for the equilibrium price due to search frictions. This risk of delay then translates into an equilibrium liquidity premium on bond purchases. As a consequence, the equilibrium price is lower - and the associated yield higher than the price that would prevail in a frictionless world. Within this model, central bank interventions can affect bond yields by reducing the liquidity premium via two channels. A stock channel works via the reduction in the overall supply of bonds in the market. As fewer bonds are available for sale, it becomes less likely that these bonds are in the hands of agents who would like to sell. The flow channel, instead, is characterised by central bank purchases taking bonds immediately out of the hands of impatient bondholders. As the most impatient and risk-averse agents are driven out of the market, the liquidity risk premium commanded by the remaining agents should decrease. So the model provides a theoretical justification for the existence of a permanent stock effect and a temporary flow effect of asset purchases by central banks (see below for a discussion of their empirical evidence).

\subsubsection{Effectiveness}

\section{Caveats}

As pointed out by Kozicki et al. (2011), research on the effectiveness of unconventional monetary policy faces several problems. First, central banks and fiscal authorities in many countries were simultaneously announcing and undertaking several policy initiatives, making it difficult to single out the effect of unconventional policies ${ }^{20}$. Also regulatory changes will impact the effectiveness of unconventional monetary policy ${ }^{21}$. Second, the reaction of financial markets

20 A case in point is the announcement of SMP on 10 May 2010, which was nearly simultaneous with the agreement on establishment of the EFSF, and only one week later than agreement on the first EU/IMF program for Greece.

21 Van den End (2012) examines what happens if banks would adjust to Basel III, by holding a higher stock of liquid assets. In particular a narrowly defined liquidity buffer - made up by high quality government bonds makes a big difference in limiting the tail risks of banks. The flip side of larger liquid bond holdings is that monetary policy conducted through asset purchases gets more influence on banks relative to extended refinancing operations. 
to these policy initiatives may have changed over time. For instance, whereas initially fiscal stimulus was considered as a stabilizing force, concerns about sovereign indebtedness in some regions may have changed this when the crisis lingered on. Likewise, there is some evidence suggesting that yield changes on key assets at the time of past asset purchase programme announcements are less than those of more recent programme announcements (Ehlers and Sushko (2012)). Third, potentially long and variable policy lags complicate the assessment. Unconventional monetary policies during crisis periods may have more immediate effects through the expectations channels in addition to effects through the standard channels of transmission. Fourth, the ongoing nature of the crisis makes it hard to determine what the evolution of economic and financial conditions would have been in the absence of policy responses. Fifth, whereas a particular policy initiative may have been designed primarily to mitigate a specific challenge, they may have spill over effects across markets. Similarly, policies of one country may have spill over effects in other countries.

Apart from these identification problems, Kozicki et al. (2011, p. 14) point out that "most studies tend not to discuss the possible negative externalities arising from these measures, including potential financial market distortions, issues related to balance sheet management and, ultimately, concerns with respect to central bank credibility and independence. Thus, conclusions drawn from studying the effects of unconventional monetary policies must be treated with appropriate caution." With this caveat in mind, we now turn to the evidence.

\subsubsection{Liquidity Support}

In the literature various empirical methods are used to identify the effectiveness of extended liquidity support, ranging from straightforward regression analysis to structural vector autoregressive (SVAR) models. The overall conclusion is that central banks' liquidity support has significantly reduced money market rates and thereby supported financial transmission and the economy.

Several papers have used Vector Autoregression (VAR) models to examine the impact of the ECB's unconventional policies. Frank and Hesse (2009) estimate a VAR model for changes in the US and euro area Libor-OIS spreads. Libor fixings in euros and US dollars are likely to display substantial interdependencies. The LTROs by the ECB is used as an explanatory variable, whereby differentiation is also made between the announcement and the actual implementation dates. The model is estimated for the crisis period spanning from July 1, 2007 until April 3, 2008. Although the authors find that the announcement of the LTROs by the ECB has a statistically significant effect, its economic magnitude is small (only 5 basis point reduction in the European market). 
Cihak et al. (2009) use a VAR-based model that additionally imposes a no-arbitrage condition as commonly applied in affine term structure finance models. The model comprises four macroeconomic variables as state variables: (i) the output gap; (ii) year-on-year inflation; (iii) the monthly average EONIA rate; and (iv) the one-year Euribor interest. Data are monthly observations from January 1999 to January 2009. The yields predicted by the model track actual bond yields very closely, but the residuals sharply turned negative in October 2008, when the ECB introduced a host of new non-standard measures. These results suggest that the ECB's policy actions during the crisis had some effect on yields.

Lenza et al. (2010) examine the impact of the ECB's unconventional policy measures by constructing counterfactual paths for the main macroeconomic variables under two scenarios: (a) a no policy scenario (to be understood as a scenario where non-standard measures are not implemented); and (b) a policy scenario, where that spread is reduced by policy intervention through the introduction of non-standard measures (where it is assumed that this scenario is captured by the path of money market rates observed in reality). The model parameters are estimated from January 1991 until the end of 2007, before the non-standard policies were implemented. Their results suggest that without the unconventional policies the 3 months ( 12 months) interest rates would have been approximately 200 (100) basis points higher in June 2009. The effect of non-standard measures on consumer loans and loans for housing purchases is large and positive, while the effect on loans to non-financial corporations becomes positive only after a delay. The authors conclude that "our results suggest that the non-standard measures have played a quantitatively significant role in stabilizing the financial sector and economy after the collapse of Lehman Bros., even if insufficient to avoid a significant fall in economic and financial activity" (p. 329).

These conclusions are underlined by the analysis conducted by Fahr et al. (2011) who estimate a structural vector autoregressive (SVAR) model for the euro area with the aim to identify different shocks hitting the economy and the financial system. Their model includes twelve macroeconomic and financial variables with monthly data over the period January 1999 until June 2010. Fahr et al. find that a financial shock, i.e. a shock that affects the interbank lending spread, plays an important role in explaining the 2008-2009 recession. Moreover, they find that a financial shock can be absorbed by banks if the central banks chooses to accommodate the ensuing increase in banks' demand for liquidity. These conclusions are supported by a counterfactual analysis using the DSGE model developed by Christiano et al. (2010) which includes a banking and financial sector. These counterfactual analyses confirm that the unprecedented increase in the demand for liquidity would have led to a marked deterioration in interbank lending conditions in absence of central bank intervention, which would have impacted broader macroeconomic conditions. 
Peersman (2011) also estimates a SVAR model for the Euro area economy with monthly data over the sample period 1999-2009. Within this SVAR, he identifies three possible sources of disturbances at the supply side of the credit market: (i) innovations to credit supply that are independent of a policy action, (ii) credit supply shocks resulting from a shift in the monetary policy rate, and (iii) innovations to credit supply caused by monetary policy actions that are orthogonal to the policy rate (unconventional monetary policy shocks). Compared to the effects of traditional interest rate innovations, Peersman finds similar macroeconomic consequences of an unconventional policy shock. The magnitude of the impact on economic activity is, for instance, similar for a 25 basis points decline in the policy rate or a 10 percent increase in the monetary base which is orthogonal to the policy rate. The transmission mechanism, however, turns out to be different for both instruments. Whilst the effects on economic activity and consumer prices reach a peak after about one year for interest rate innovations, this is more than six months later for innovations to the monetary base. Furthermore, bank interest rate spreads increase significantly after an expansionary interest rate innovation, whereas spreads persistently decline after an action which raises the size of the Eurosystem's balance sheet.

A potential problem with single-country VAR studies is that they rely on models estimated over sample periods covering also the pre-crisis period, which may not be adequate for assessing monetary transmission in a liquidity trap. Therefore, Gambacorta et al. (2012) estimate a panel structural vector autoregressive (SVAR) model over a sample period during which unconventional policies were implemented in Canada, the euro area, Japan, Norway, Sweden, Switzerland, the United Kingdom and the United States. The sample period is January 2008 until June 2011. The authors conclude that an expansionary unconventional monetary policy shock leads to a significant but temporary rise in output and prices. While the output effects are qualitatively similar to the ones typically found in the literature on the effects of conventional monetary policy, the impact on the price level seems to be less persistent and weaker. They do not find major cross-country differences in the macroeconomic effects of shocks to central bank balance sheets, despite the different measures that were taken in response to the crisis. Since the panel analysis is based on a mean group estimator, it also yields individual country estimates. They find that the euro area results are very similar to those obtained by Peersman (2011).

Finally, Darracq Pariès and De Santis (2013) assess the effects of the 3-year LTROs. These authors identify the implied non-standard monetary policy shock through the Bank Lending Survey (BLS) information for the beginning of 2012, assuming that the main transmission channel of the LTROs works through the mitigation of liquidity and funding risks in the euro area banking system. They estimate a panel-VAR for the euro area countries, which include relevant BLS 
variables, and find that that the 3-year LTROs significantly lifted prospects for real GDP and loan provision to non-financial corporations over the next two-tothree years.

An alternative approach is the event study methodology which has some advantages and disadvantages (Ait-Sahalia et al. (2012)). The most important advantages are its simplicity, parsimony, and focus on the immediate market response to an event, i.e. a policy announcement. Event studies are better designed to deal with issues such as limited sample size and model specification. Their main disadvantages are that they do not address causality and that they cannot provide a comprehensive evaluation of policy effectiveness.

Ait-Sahalia et al. (2012) apply the event study approach, focusing on the period June 1, 2007-March 31, 2009. Their database covers announcements of authorities in the United States, the United Kingdom, the euro area, and Japan in the area of fiscal policy, monetary policy (including liquidity support) and financial sector policy. Their main indicator of financial distress is the change in the spread between London Interbank Offered Rates (LIBOR) and Overnight Index Swaps (OIS) for the US dollar. The results of Ait-Sahalia et al. (2012) do not yield strong evidence that domestic liquidity support helped relieve pressures in the interbank markets: announcements of domestic currency liquidity support were associated with a decline in the Libor-OIS spread, but the statistical significance of this result diminishes when the event window is narrowed. Announcements of forex swaps were associated with significant declines in interbank risk premia.

Angelini et al. (2011) use regression analysis to examine interbank rates as these are a key part of the monetary policy transmission mechanism. Using a unique data set based on the e-MID (a screen-based trading facility used by Italian and other European banks to exchange uncollateralized interbank funds) between January 25, 2005 and December 31, 2008, the authors regress interest rates spreads on a set of market-wide and bank-specific variables. They include dummy variables equal to 1 on the day of the announcement of exceptional long-term refinancing operations (1-, 3-, and 6-month maturity) launched by the ECB after August 2007. The results suggest that the exceptional ECB interventions dampened the spread only after the Lehman failure: the impact effect was about -10 and 15 basis points for the 3 - and 1-month special refinancing operations, in that order.

Abbassi and Linzert (2011) analyze the effectiveness of monetary policy in steering euro area money market rates using two measures: first, the predictability of money market rates on the basis of monetary policy expectations, and second the impact of extraordinary central bank measures on money market rates. Their sample periods are 10 March 2004-8 August 2007 (pre-crisis) and 9 August 200730 June 2009 (crisis). Abbassi and Linzert argue that for an effective monetary policy, it is crucial that interest rate expectations are in line with the central bank 
policy intentions and are correctly reflected in the shape of the yield curve. Likewise, if non-standard monetary policy measures were effective, they should lower the tensions in money markets. These authors report that market expectations about monetary policy are less relevant for money market rates up to 12 months after August 2007 compared to the pre-crisis period. In addition, they find that the ECB's net increase in outstanding open market operations as of October 2008 accounts for at least a 100 basis point decline in Euribor rates.

\subsubsection{SMP}

In his overview paper, Manganelli (2012) concludes that while studies about the effectiveness of the SMP rely on different methodologies and data frequencies the asset purchases had a positive but short-lived effect on market functioning by reducing liquidity premia and lowering the level as well as the volatility of yields.

Baumeister and Benatti (2010) explore the macroeconomic impact of a compression in the long-term bond yield spread within the context of the Great Recession of 2007-2009 via Bayesian time-varying parameter structural VARs for the Euro area, the United States, Japan, and the United Kingdom. They identify a 'pure' spread shock which, leaving the short-term rate unchanged by construction, allows them to characterise the macroeconomic impact of a compression in longterm yield spreads induced by central banks' asset purchase programmes within a zero lower bound environment. The authors conclude that a compression of the long-term yield spread exerts a powerful effect on both output growth and inflation. They also conclude that the asset purchase programmes in the US and the UK have averted significant risks both of deflation and of output collapses comparable to those that took place during the Great Depression. They do not examine the effects of the SMP, but three recent papers do.

De Pooter et al. (2012) examine whether the SMP had an impact on sovereign bond liquidity premia. For that purpose they use a term structure model to decompose bond prices into parts describing the risk-free rate, default intensity, and a liquidity premium. They use the difference between the default probability according to CDS and bonds as measure of the liquidity premium. The risk-free rate is measured by relevant maturity German bond yields ${ }^{22}$. The ECB made SMP purchases off and on over a long period of time and made these purchases in five distinct sovereign markets beginning with Greece, Ireland and Portugal in May 2010 and then expanding the program to Spain and Italy on August 7, 2011. The structure of these purchases allows the authors to exploit both cross-section and time series elements of the data. Using data for the sample January 1, 2009

\footnotetext{
22 Thereby neglecting a flight-to-quality effect.
} 
through February 29, 2012, the authors find a 19.4 basis point impact decline of the liquidity premium to a purchase of one percent of debt outstanding - of which 14.8 basis points is temporary. The permanent effect is therefore 4.6 basis points; this effect is highly significant.

Kilponen et al. (2012) study daily price data of 7 countries in the euro area and find that among 55 different European policy decisions between 2007 and 2012, the announcement of SMP had the most significant effects on 10-year sovereign bond yields.

Ghysels et al. (2012) analyse the high-frequency dynamics of bond yields and ECB purchases of sovereign bonds. By matching the timing and amounts purchased with the prevailing intraday quotes at sufficiently high frequency, the authors are able to isolate the immediate effect of the purchases from the impact of the other shocks that hit the market during the rest of the day. When the authors regress yield changes on SMP interventions at 15-minute intervals, they find that a EUR 100 million intervention has an immediate impact on bond yields of between 0.1 and 25 basis points, depending on the size of the market.

Finally, Eser and Schwaab (2012) use a panel of daily data for bond yields and SMP interventions. If both ECB bond purchases and yield developments react to an unobserved news flow, regressing yield changes on SMP purchases gives rise to an endogeneity problem. To deal with this problem, the authors adopt a factor modeling methodology using as controls both observed and unobserved factors that can approximate the unobserved news flow affecting yield developments. The observed factors used in the analysis are the VIX volatility and the spread between BBB and AAA-rated corporate bonds in the euro area. The latent factors include a common and a country-specific component, which should account for both common and idiosyncratic shocks. The authors find that, on average, a daily SMP intervention of EUR 100 million lowered yields by 0.1 to 2 basis points. In addition, SMP purchases have significantly contributed to lower yield volatility. The cumulated persistent effect over time of a total purchase of EUR 50 billion results in a cumulative reduction in yields of approximately 90 basis points for large countries and 1,000 basis points for smaller countries.

\subsection{NeW EVIDENCE ON THE EFFECTIVENESS OF UnCONVENTIONAL Policies OF THE ECB}

The ECB's SMP focused more narrowly on stabilizing securities markets, as opposed to quantitative easing by, for instance, the $\mathrm{Fed}^{23}$. In order to examine

23 For recent analyses of the Fed's policies, we refer to Gagnon et al. (2011), D'Amico and King (2012) and D'Amico et al. (2012). 
how effective the SMP has been, we follow Eser and Schwaab (2012) and use a panel of daily bond yields, CDS spreads and other market data, over the period June 2010 to June 2012. We extend their analysis by using a different and innovative method to extend the factor analysis results and calculate hypothetical yields. In addition, we assess both the impact of ECB (SMP, MROs, LTROs) and EFSF interventions, as measured by weekly outstanding volumes. For the SMP, MROs and LTROs, we take weekly changes in volumes of the overall portfolios, while for EFSF we take the effective size of the facility, which was raised at European Summits in Brussels (July 2011) and Copenhagen (March 2012). We restrict ourselves to a simple impact analysis and do not assess potential channels through which the interventions impact market prices. Needless to say, our estimations are surrounded by considerable model and estimation uncertainty, as is usual in this kind of analyses.

Factor analysis allows us to disentangle a smaller number of latent (unobserved) factors which drive the observed variables. The observed variables are estimated as a linear combination of unobserved factors and coefficients, or factor loadings. We seek to explain the 10 year government bond yields of peripheral euro area countries, including both control variables (CDS spreads, money market spreads, stock price indices, exchange rates and volatility indicators) and the impact of policy interventions such as MROs, LTROs, SMP and the EFSF. The methodology yields factor loadings for each variable, which can be clustered based on significance. Loadings above 0.6 are considered significant, as are factors with an eigen value above 1.0. Where a factor shows positive loadings with the intervention, and negative loadings with spreads, it can be judged to be the desired "implementation effect" of a policy intervention.

Table 4.3 shows the coefficients of the factor analysis. It is immediately apparent that there is a strong common driver behind the CDS spreads and bond yields of peripheral euro area countries, interbank spreads and broader credit spreads of EU banks. Factor 1 can thus be interpreted as "peripheral credit risk", which is itself a driver of SMP intervention. Both the SMP and credit spreads have a positive correlation with factor 1 , as an indication of the endogeneity issue. Most of these variables show a slight negative correlation with factor 2, which is driven by the MSCI World and Europe stock indices and (negatively) by volatility as measured by the VIX index. We thus interpret factor 2 as "global stock market conditions". Factor 3 shows common drivers behind the bond yields of Spain and Ireland, which both experienced a severe banking crisis and hence had correlated idiosyncratic risks. We interpret factor 4, meanwhile, as "effect of the Eurosystem's MROs and LTROs"; the two are negatively correlated with one another due to their substitution for one another over time. The Eurosystem interventions show strong correlation with the volatility of the dollar/euro exchange rate, indicating that the interventions influenced risk perceptions of break-up scenarios. 
They also have some negative correlation (circa 0.2) with the CDS of peripheral countries, indicating an implementation effect. Finally, factor 5 represents "effect of EFSF", which is strongly correlated with Greek CDS - given that increases in the capacity of the EFSF have been decided at the same moments that credit concerns around Greece have come to a head. This factor also shows small positive (0.1-0.4) correlation with CDS spreads of peripheral countries, meaning that the endogeneity problem dominates over the implementation effect. Overall, the fact that none of the factors with strong loadings for policy interventions have opposite signs for the loadings for bond yields and credit spreads means that, prima facie, the long-term implementation effect is not strong, particularly for the SMP and EFSF.

In order to better understand the effects of interventions, we go one step further, using the output from the factor analysis. The autonomous impact of policy intervention can be teased out by generating a hypothetical yield which excludes the effect of intervention. We first calculate the partial correlation coefficient $p$, which represents the correlation between the 10 year yield $(Y)$ and the interventions $(X)$, adjusted for the effects of all other variables:

$X=\operatorname{Re} g\left(X_{1}, X_{2}, X_{3}, \ldots, X_{n}\right)$ without $Y:$ residuals $R_{X}$

$Y=\operatorname{Re} g\left(X_{1}, X_{2}, X_{3}, \ldots, X_{n}\right)$ without $X$ : residuals $R_{Y}$

where partial correlation $p=\operatorname{corr}\left(R_{x}, R_{y}\right)$. It also follows from the regression of the residuals,

$R_{y}=a+b * R_{x}=b^{*} R_{x}$.

To determine $p$, we can use variances, whereby the coefficient of determination is:

$R^{2}=\frac{\operatorname{var}\left(R_{x}\right)}{\operatorname{var}\left(R_{y}\right)}$

where square root $R^{2}$ equals $p$ and $1 / \mathrm{b}$. The effect of interventions is $b * R_{x}$ which is the difference between the actual yield $(Y)$ and a hypothetical $Y-b * R_{x}$ yield that excludes this effect.

The difference between the actual and hypothetical yield reflects the autonomous impact of policy intervention. A negative difference indicates that the actual yield is lower than the hypothetical counterfactual without intervention. These calculations (not shown) suggest that the increases in the effective size of the EFSF in July 2011 and March 2012 seem to have had large downward impact on the bond yields. The increases lowered bond yields of Italy, Portugal and Spain compared 
to the hypothetical yield without intervention to the order of 30 to 60 basis points, and even more for Greece and Ireland.

Table 4.3: Coefficients of factor analysis

\begin{tabular}{llllll}
\hline & Factor1 & Factor2 & Factor3 & Factor4 & Factor5 \\
\hline Italian CDS & 0.90 & 0.07 & -0.17 & -0.21 & 0.26 \\
Greek bond yield & 0.90 & -0.14 & 0.06 & -0.02 & 0.23 \\
SMP & 0.89 & -0.18 & -0.04 & -0.18 & 0.35 \\
Spanish CDS & 0.87 & 0.05 & 0.08 & -0.20 & 0.26 \\
Portuguese CDS & 0.83 & -0.20 & 0.12 & -0.23 & 0.37 \\
Interbank spread & 0.81 & -0.45 & -0.06 & 0.25 & -0.13 \\
Portuguese bond yield & 0.81 & -0.18 & 0.43 & -0.17 & 0.16 \\
Italian bond yield & 0.80 & -0.27 & 0.38 & 0.06 & 0.13 \\
Irish CDS & 0.79 & -0.15 & 0.49 & -0.01 & 0.01 \\
EU bank CDS & 0.76 & -0.47 & 0.18 & 0.11 & 0.26 \\
EU sovereign CDS & 0.56 & -0.54 & 0.44 & 0.28 & -0.07 \\
\hline MSCI Europe Index & -0.38 & 0.88 & 0.15 & -0.05 & -0.20 \\
MSCI World Index & -0.01 & 0.85 & 0.39 & -0.27 & 0.02 \\
VIX Index & 0.12 & -0.81 & 0.18 & 0.05 & 0.13 \\
Irish bond yield & 0.04 & 0.16 & 0.95 & 0.10 & -0.13 \\
Spanish bond yield & 0.44 & -0.05 & 0.63 & -0.03 & 0.41 \\
\hline MRO volume & -0.14 & -0.20 & -0.01 & 0.89 & -0.17 \\
EUR/USD volatility & 0.04 & -0.55 & 0.12 & 0.66 & -0.12 \\
LTRO volume & 0.44 & -0.09 & -0.28 & -0.58 & 0.56 \\
\hline Greek CDS & 0.41 & -0.10 & -0.03 & -0.22 & 0.82 \\
EFSF volume & 0.52 & -0.33 & 0.09 & -0.35 & 0.55 \\
\hline & & & & & \\
\hline Eigen value & 8.34 & 3.60 & 2.48 & 2.18 & 2.16 \\
\hline
\end{tabular}

MSA model $=0.81$ (Kaiser-Myer-Olkin (KMO) measure of sampling adequacy)

Interpretation:

Factor 1: "peripheral credit risk

Factor 2: "global stock market conditions"

Factor 3: "idiosyncratic Spanish and Irish bond market risk"

Factor 4: "effect of the Eurosystem's MROs and LTROs"

Factor 5: "effect of EFSF"

The same holds for the December 2011 and especially February 2012 three year LTROs, which appear to have lowered yields by 10 to 50 basis points for Italy, or as much as $150 \mathrm{bp}$ for Portugal (see Figure 4.10). Yet conspicuously, this positive effect often lasts only for a matter of weeks before dissipating or even reversing. For Greece, estimations are extremely volatile and - with the exception of the 
re-start of the SMP in Summer 2011, when yields fell by 400bp compared to the hypothetical - show little consistency with the expected effects of European-level interventions. This highlights that Greece - so often a driver of European action against the debt crisis - remains a different case when it comes to policy impact.

Figure 4.10: Effect of LTRO: Actual vs. Hypothetical bond yields for GIIPS countries
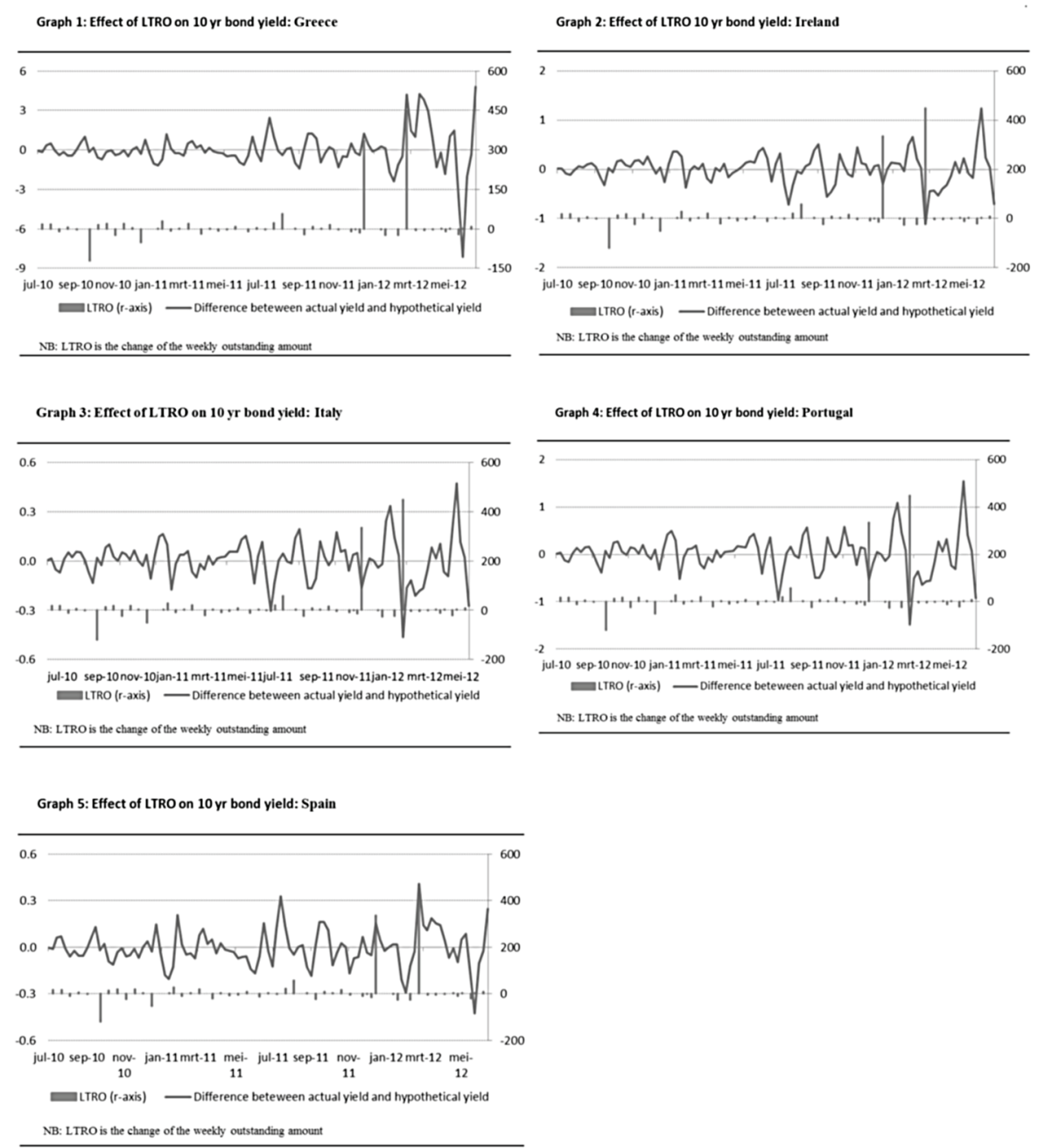

The outcomes show that the EFSF and LTRO interventions in general had a favorable (short-term) effect on government bond yields. 10-year sovereign yields in Italy, Spain, Portugal and Ireland declined after a substantial increase in EFSF or LTRO outstandings. Only the bond yield of Greece reacted differently. Changes in the SMP only had a visible downward effect on bond yields in Summer 2011, 
when the program was reactivated for Italy and Spain (see Figure 4.11). However this seems limited to a temporary effect only, which dissipated within a few weeks of the intervention. This is in line with the findings in other studies, such as De Pooter et al. (2012), in which the permanent impact is much smaller than the initial impact (see Section 4.3.).

Figure 4.11: Effect of SMP: Actual vs Hypothetical bond yields for GIIPS countries
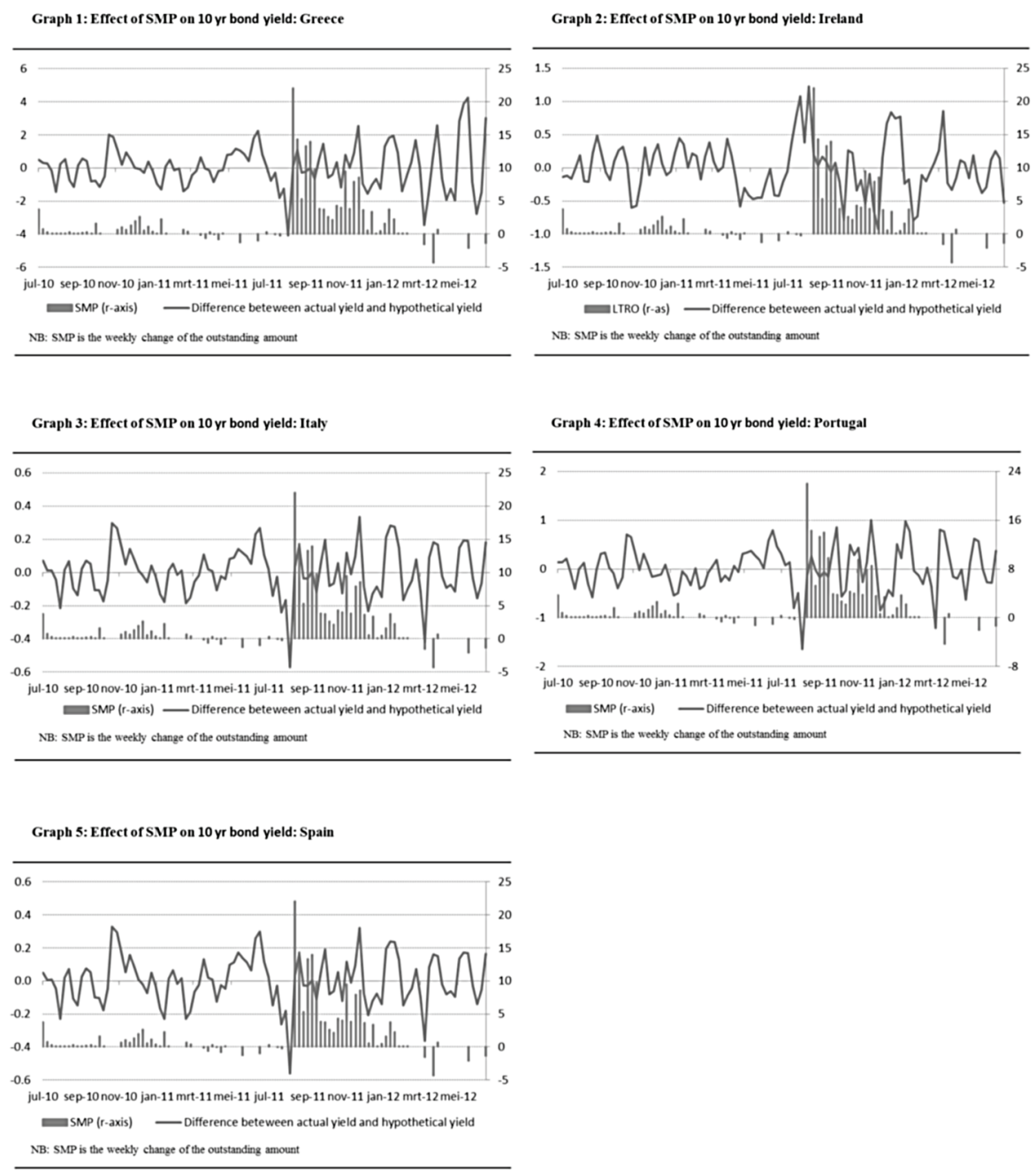

Recent experience shows that central bank and government policy actions can have significant effects - both positive and negative - on credit spreads. For example, ECB President Draghi's 26 July 2012 comments that the ECB's actions "will be enough" to protect the solidity of the euro led to a sustained fall in peripheral 
bond yields, as did the announcement of Outright Monetary Transactions (OMTs) on 6 September 2012. The scale of the market reaction, which occurred without actual activation, is more likely to stem from a signalling effect - albeit through expectations of future asset purchases, rather than through interest rate decisions. On the other hand, negative news on the (lack of) outcome of Eurogroup discussions on Greece (22 November 2012) or political turmoil in Italy (December 2012) caused spreads to rise. The size and sustainability of these effects can be unpredictable, given that they depend in large part on market perceptions about inherently uncertain tail risk scenarios. Overall, we conclude that the most important unobserved variable - trust by the markets in the credibility of policy - is likely driving both the absolute value of spreads and the extent to which central bank policy interventions are effective in lowering spreads.

\subsection{CONCLUSIONS}

In this contribution we have first sketched how central banks have used unconventional monetary policy measures by using three indicators based on the composition of the balance sheet of eleven central banks. Our analysis suggests that although the ECB's balance sheet has increased dramatically during the crisis, the non-standard monetary policy measures had only a moderate impact on the composition of the ECB's balance sheet compared to other central banks, such as the Fed and the Bank of England.

Next, we have taken stock of research analysing the effects of unconventional monetary policy of the ECB after the onset of the crisis. A crucial question is to what extent these measures have been able to affect interest rates, thereby restoring the monetary policy transmission process and supporting the central bank objectives. We find that various empirical methods are used to identify the effectiveness of extended liquidity support, ranging from straightforward regression analysis to structural vector autoregressive (SVAR) models. While this adds to a divergence of results, the overall conclusion is that central banks' liquidity support has significantly reduced money market rates and thereby supported financial transmission and the economy. Likewise, studies about the effectiveness of the SMP rely on different methodologies and data frequencies but generally conclude that the asset purchases had a positive but short-lived effect on market functioning by reducing liquidity premia and lowering the level as well as the volatility of yields.

Finally, we have offered new evidence on the effectiveness of the ECB's unconventional monetary policy measures, i.e. extended liquidity provision (LTRO) and the Securities Market Programme (SMP). The results suggest that the LTRO interventions in general had a favorable (short-term) effect on government bond 
yields. Changes in the SMP only had a visible downward effect on bond yields in Summer 2011, when the program was reactivated for Italy and Spain, but this effect dissipated within a few weeks.

\section{REFERENCES}

AbBassi, P. and LinZert, T., 2011, "The Effectiveness of Monetary Policy in Steering Money Market Rates During the Recent Financial Crisis", ECB Working Paper 1328.

AÏT-SAhalia, Y., ANDritzKy, J., JobSt, A., NOWAK, S. and TAMIRISA, N., 2012, "Market Response to Policy Initiatives during the Global Financial Crisis", Journal of International Economics, 87, 162-177.

ANgelini, P., Nobili, A. and Picillo, Ch., 2011, "The Interbank Market after August 2007: What Has Changed, and Why?", Journal of Money, Credit and Banking, 43, 923-958.

Baumeister, Ch. and Benati, L., 2010, "Unconventional Monetary Policy and the Great Recession-Estimating the Impact of a Compression in the Yield Spread at The Zero Lower Bound", ECB Working Paper 1258.

Beirne, J., Dalitz, L., Ejsing, J., Grothe, M., Manganelli, S., Monar, F., SAHEL, B., SUŠCEC, M., TAPKING, J. and VONG, T., 2011, "The Impact of the Eurosystem's Covered Bond Purchase Programme on the Primary and Secondary Markets”, ECB Occasional Paper No. 122.

Benati, L. and Goodhart, Ch., 2010, "Monetary Policy Regimes and Economic Performance: The Historical Record, 1979-2008" in B.M. FRIEDMAN and M. WOODFORD (Eds.), Handbook of Monetary Economics, pp. 11591236, Elsevier, Amsterdam.

Bernanke, B., 2006, Monetary Aggregates and Monetary Policy at the Federal Reserve: A Historical Perspective, Board of Governors of the FED, Washington DC.

Beyer, A., Gaspar, V., Gerberding, Ch. and Issing, O., 2009, "Opting Out of the Great Inflation: German Monetary Policy after the Break Down of Bretton Woods", ECB Working Paper 1020.

Blinder, A.S., Ehrmann, M., Fratzscher, M., De HaAn, J. and Jansen, D.-J., 2008, "Central Bank Communication and Monetary Policy: A Survey of Theory and Evidence", Journal of Economic Literature, 46, 910-45.

Borio, C. and Disyatat, P., 2010, "Unconventional Monetary Policies: An Appraisal", The Manchester School, 78(s1): 53-89.

BrunNer, K. and Meltzer, A.H., 1993, Money and the Economy: Issues in Monetary Analysis, Cambridge University Press, Cambridge. 
Christiano, L., Motto, R. and Rostagno, M., 2010, "Financial Factors in Economic Fluctuations", ECB Working Paper 1192.

Cihák, M., Harjes, Th. and Stavrev, E., 2009, "Euro Area Monetary Policy in Uncharted Waters", IMF Working Paper 09/185.

CuRdíA, V. and WoOdFord, M., 2011, "The Central-Bank Balance Sheet as an Instrument of Monetary Policy", Journal of Monetary Economics, 58(1), 54-79.

D’Amico, S., English, W., LopeZ-Salido, D. and Nelson, E., 2012, “The Federal Reserve's Large-Scale Asset Purchase Programs: Rationale and Effects", Federal Reserve Finance and Economics Discussion Series 2012-85.

D’Amico, S. and KING, T.B., 2012, "Flow and Stock Effects of Large-scale Treasury Purchases: Evidence on the Importance of Local Supply", Journal of Financial Economics, forthcoming, http://dx.doi.org/10.1016/j.jfineco.2012.11.007.

DarracQ-Parries, M. and De SANTIS, R., 2013, "A Non-Standard Monetary Policy Shock: The ECB's 3-year LTROs and the Shift in Credit Supply", ECB Working Paper 1508.

De HaAn, J., Oosterloo, S. and Schoenmaker, D., 2012, Financial Markets and Institutions: A European Perspective, Cambridge, Cambridge University Press.

De Pooter, M., Martin, R.F. and PruitT, S., 2012, The Effects of Official Bond Market Intervention in Europe. Federal Reserve Board of Governors. Available at: http://papers.ssrn.com/sol3/papers.cfm?abstract_id=2143326.

Eggertsson, G. and Woodford, M., 2003, “The Zero Bound on Interest Rates and Optimal Monetary Policy", Brookings Paper on Economic Activity 1, pp. 139-211.

EHLERS, T. and SushKo, S., 2012, "Unconventional Policies: Market Impact and Countervailing Factors", BIS Quarterly Review, September 2012, 6-7.

Eser, F. and SCHWAAB, B., 2012, The Yield Impact of Central Bank Asset Purchases: The Case of the ECB's Securities Markets Programme, ECB, mimeo.

European Central Bank, 2011, The Monetary Policy of the ECB, Frankfurt, ECB.

Fahr, S., Motto, R., Rostagno, M., Smets, F. and Tristani, O., 2011, “A Monetary Policy Strategy in Good and Bad Times: Lessons from the Recent Past”, ECB Working Paper 1336.

Frank, N. and Hesse, H., 2009, "The Effectiveness of Central Bank Interventions during the First Phase of the Subprime Crisis", IMF Working Paper 09/206.

Friedman, M., 1968, "The Role of Monetary Policy", American Economic Review, 58 (1), 1-17. 
Gagnon, J., Raskin, M., Remache, J. and SACK, B., 2011, "The Financial Market Effects of the Federal Reserve's Large-Scale Asset Purchases", International Journal of Central Banking, 7(1), 3-43.

Gambacorta, L., Hofmann, B. and Peersman, G., 2012, “The Effectiveness of Unconventional Monetary Policy at the Zero Lower Bound: A Cross-Country Analysis" BIS Working Papers 384.

Ghysels, E., IDier, J., Manganelli, S. and Vergote, O., 2012, A High Frequency Assessment of the ECB Securities Markets Programme, ECB, mimeo.

GonZÁlez-PÁRAmo, J.M., 2011, The ECB and the Sovereign, Speech at the XXIV Moneda y Crédito Symposium, 4 November 2011.

Greenwood, R. and Vayanos, D., 2008, "Bond Supply and Excess Bond Returns", NBER Working Paper 13806.

Hannoun, H., 2012, Monetary Policy in the Crisis: Testing the Limits of Monetary Policy, Speech at 47th SEACEN Governors' Conference Seoul, Korea, 13-14 February 2012.

Hilbers, P., 1998, "Financial Sector Reform and Monetary Policy in the Netherlands", IMF Working Paper 98/19.

INTERNATIONAL MONETARY FUND (IMF), 2009, "Market Interventions During the Financial Crisis: How Effective and How to Disengage", Global Financial Stability Report, October.

Johnson, H.G., 1971, “The Keynesian Revolutions and the Monetarist Counter-Revolution”, American Economic Review, 61 (2), 91-106.

Joyce, M., Tong, M. and Woods, R., 2011, “The United Kingdom's Quantitative Easing Policy: Design, Operation and Impact”, Bank of England Quarterly Bulletin 2011 Q3.

Kilponen, J., LAAKKonen, H. and Vilmunen, J., 2012, "Sovereign Risk, European Crisis Resolution Policies and Bond Yields", Bank of Finland Research Discussion Paper 22.

Klyuev, V., De Imus, Ph. and SRinivasan, K., 2009, "Unconventional Choices for Unconventional Times Credit and Quantitative Easing in Advanced Economies”, IMF Staff Position Note 2009/27, October.

Kozicki, S., SANTOR, E. and SuCHANEK, L., 2011, "Unconventional Monetary Policy: The International Experience with Central Bank Asset Purchases", Bank of Canada Review, Spring 2011, 13-25.

LenZA, M., Reichlin, L. and Pill, H., 2010, “Monetary Policy in Exceptional Times”, Economic Policy, April 2010, 295-339.

Manganelli, 2012, “The Impact of the Securities Markets Programme”, ECB Research Bulletin 17. 
Mishrin, F.S. and SAvastano, M.A., 2001, "Monetary Policy Strategies for Latin America", Journal of Development Economics, 66(2), 415-444.

Peersman, G., 2011, "Macroeconomic Effects of Unconventional Monetary Policy Measures in the Euro Area", ECB Working Paper 1397.

SAMARYNA, A. and DE HAAN, J., 2013, "Right on Target: Exploring the Factors Leading to Inflation Targeting Adoption", Contemporary Economic Policy, forthcoming.

SACHS, J., 2012, "We Must Look Beyond Keynes to Fix Our Problems", Financial Times, December 18, 2012, p. 9.

Stone, M., FujitA, K. and IsHi, K., 2011, "Should Unconventional Balance Sheet Policies be Added to the Central Bank Toolkit? A Review of the Experience So Far", IMF Working Paper 11/145.

SVENSSON, L.E.O., 1997, "Inflation Forecast Targeting: Implementing and Monitoring Inflation Targets", European Economic Review, 41(6), 1111-1146.

Vayanos, D. and Vila, J.-L., 2009, "A Preferred-habitat Model of the Term Structure of Interest Rates”, NBER Working Paper 15487.

VAN DEN END, J.W., 2012, "Liquidity Stress-tester: Do Basel III and Unconventional Monetary Policy Work?”, Applied Financial Economics, 22(15), 1233-1257. 